Elsevier required licence: (c) <2019>.

This manuscript version is made available under the CC-BY-NC-ND 4.0 license

http://creativecommons.org/licenses/by-nc-nd/4.0/

The definitive publisher version is available online at

https://www.sciencedirect.com/science/article/pii/S0899825619300326?via\%3Dihub 


\section{Accepted Manuscript}

Loss Aversion and Competition in Vickrey Auctions: Money Ain't No Good

Antonio Rosato, Agnieszka A. Tymula

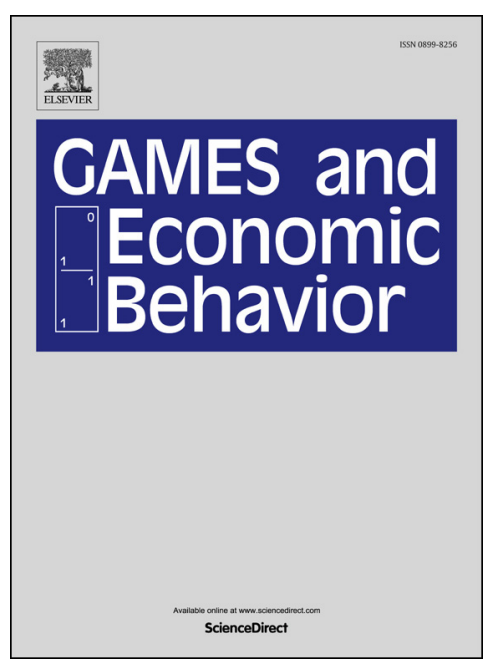

PII: $\quad$ S0899-8256(19)30032-6

DOI: $\quad$ https://doi.org/10.1016/j.geb.2019.02.014

Reference: $\quad$ YGAME 2965

To appear in: Games and Economic Behavior

Received date: 8 April 2017

Please cite this article in press as: Rosato, A., Tymula, A.A. Loss Aversion and Competition in Vickrey Auctions: Money Ain't No Good. Games Econ. Behav. (2019), https://doi.org/10.1016/j.geb.2019.02.014

This is a PDF file of an unedited manuscript that has been accepted for publication. As a service to our customers we are providing this early version of the manuscript. The manuscript will undergo copyediting, typesetting, and review of the resulting proof before it is published in its final form. Please note that during the production process errors may be discovered which could affect the content, and all legal disclaimers that apply to the journal pertain. 


\title{
Loss Aversion and Competition in Vickrey Auctions: Money Ain't No Good*
}

\author{
Antonio Rosato $^{\dagger} \quad$ Agnieszka A. Tymula
}

March 13, 2019

\begin{abstract}
A key prediction of expectations-based reference-dependent preferences and loss aversion in second-price auctions with private values is that the number of bidders should affect bids in auctions for real objects but not in auctions with induced monetary values. In order to test this distinctive comparative statics prediction, we develop an experiment where subjects bid in multiple auctions for real objects as well as auctions with induced values, each time facing a different number of rivals. Our results are broadly consistent with expectations-based reference-dependent preferences and loss aversion. We find that in real-object auctions bids decline with the intensity of competition whereas in induced-value auctions, instead, bids do not vary with the intensity of competition. Our results suggest that bidders may behave differently in real-object auctions than in induced-value ones, casting some doubt on the extent to which findings from induced-value laboratory experiments can be transferred to the field.
\end{abstract}

JEL Classification: C91; C92; D03; D44; D81; D84

Keywords: Auctions; Reference-Dependent Preferences; Loss Aversion; Expectations.

*We are grateful to an advisory editor and three referees for their constructive comments and suggestions that substantially improved the paper. For helpful conversations, we also thank Ned Augenblick, Aurélien Baillon, Benjamin Balzer, Jimmy Chan, Stefano Della Vigna, Guillaume Fréchette, Stephanie Heger, Fabian Herweg, Alex Imas, Heiko Karle, Anton Kolotilin, Botond Köszegi, Maciej Kotowski, Andreas Lange, Hongyi Li, Takeshi Murooka, Andras Niedermayer, Marco Pagnozzi, Vincenzo Pezone, Annalisa Scognamiglio, Dmitry Taubinsky, Kosuke Uetake, John Wooders, Jingjing Zhang, as well as audiences at Monash, University of Sydney, UNSW, UTS, the $3^{\text {rd }}$ ATE Symposium in Auckland, ESAM 2016 in Sydney, ESEM 2016 in Geneva, ESA 2016 in Bergen, Yale SOM, CEU, UC Berkeley, University of Surrey, Erasmus University in Rotterdam, University of Edinburgh, University of Warwick, HEC Lausanne, IE Madrid, University of Bayreuth, Max Planck Institute for Research on Collective Goods (Bonn) and University of Cambridge. Rosato gratefully acknowledges financial support from the 2015 UTS Business Research Grant and the ARC-DE180100190 grant. Tymula gratefully acknowledges financial support from the University of Sydney Incubator Grant in paying for the study and the salary support from the ARC-DE150101032 grant.

${ }_{\dagger}^{\dagger}$ UTS Business School, University of Technology Sydney and CSEF (Antonio.Rosato@uts.edu.au).

${ }^{\ddagger}$ School of Economics, University of Sydney and Visiting Affiliated Faculty, Institute for the Study of Decision Making, New York University (Agnieszka.Tymula@sydney.edu.au). 


\section{Introduction}

The second-price sealed-bid auction, first introduced in Vickrey's (1961) seminal paper and hence also known as simply the Vickrey auction, is probably the most famous and easily understood auction format. It is well-known that in standard private-value auction models of fully rational bidders with standard preferences, bidding one's own value is a (weakly) dominant strategy. This theoretical prediction holds irrespective of bidders' risk attitudes, the number of bidders in the auction, symmetry (or lack thereof) in the values' distributions or whether the values are correlated. Moreover, this prediction is very robust as it holds in many different settings. For example, it continues to hold in models where bidders have non-standard (risk) preferences, i.e. anticipated regret as in Ozbay and Ozbay (2007) or ambiguity aversion as in Chen et al. (2007), or where bidders are not perfectly rational as in Crawford and Iriberri's (2007) analysis of level-k auctions.

However, if bidders have expectations-based reference-dependent preferences à la Köszegi and Rabin $(2006,2007)$ (henceforth, KR), bidding one's own value is not a dominant strategy anymore. This occurs because a bidder's beliefs about his likelihood of winning the auction, and hence his reference point, are directly affected by his competitors' strategies. Moreover, as shown by Lange and Ratan (2010), the KR model makes different predictions in auctions for real objects than in auctions with induced monetary values, the latter being the type of auctions commonly run in most laboratory experiments. ${ }^{1}$ In particular, in real-object auctions equilibrium bids should vary with the intensity of competition. Intuitively, when the number of competitors in the auction increases, ceteris paribus a bidder expects to win with a lower probability; this in turn lowers the reference point of a loss-averse bidder who feels less attached to the object and hence bids less aggressively, for a large interval of intrinsic values for the object. In induced-value auctions, instead, in the (unique) symmetric equilibrium bidders bid their value. The reason for this discrepancy in the equilibrium bids between real-object and induced-value auctions is as follows. In an auction for a real object bidders trade off feelings of loss and gain across the different dimensions of utility. For example, losing the auction feels like a loss in the product dimension and, at the same time, as a gain in money dimension compared to the possibility of winning the auction. Therefore, it is not possible for the bidder to eliminate losses on both dimensions simultaneously. With induced values, on the other hand, there is only one dimension of utility, namely money, and hence losing (resp. winning) the auction always feels like a loss (resp. gain). ${ }^{2}$

In this paper we present evidence from a laboratory experiment inspired by the theoretical work of Lange and Ratan (2010) and aimed at testing the comparative statics predictions

\footnotetext{
${ }^{1}$ See also the related work by Eisenhuth (2018) who derives the seller's revenue-maximizing mechanism in an environment with independent private values where bidders have KR preferences.

${ }^{2}$ The notion that bidders, or people more generally, assess gains and losses separately across different dimensions is related to the concept of mental (or psychological) accounting; see Thaler (1985, 1999).
} 
of the KR model in second-price private-value auctions. In the experiment, subjects took part in auctions for real objects as well as auctions with induced monetary values. For each "prize" a subject participated in three separate auctions, each time facing a different yet known number of rivals. This within-subject design allows us to see whether and how a participant's bid for a given prize changes depending on how many rivals he is facing and also to compare these changes for real-object auctions vs. induced-value ones.

At the aggregate level, our findings are broadly consistent with the predictions of the KR model. For real-object auctions we find that increasing the intensity of competition pushes bidders, on average, to bid less aggressively. In particular, for four of the six products that we used in our experiment, we find that when the number of bidders increases from three to twelve, the average bid declines by $7 \%$. Furthermore, if we exclude from the analysis those subjects who overbid in induced-value auctions, the negative effect of an increase in competition on bids in real-object auctions becomes significant for five of the six products and its magnitude doubles. In induced-value auctions, instead, we find that the intensity of competition has no significant effect on bids. Besides providing support for the KR model, these findings also suggest that bidders may behave differently in real-object auctions than in induced-value ones, thereby casting some doubt on the extent to which findings from induced-value laboratory experiments can be transferred to the field.

At the individual level, there is substantial heterogeneity in how subjects respond to changes in the number of bidders in an auction. The vast majority of subjects changed their bid when the number of bidders increases and, in line with the KR model, they changed it more often in real-object auctions than in induced-value ones. While the fraction of subjects who increased their bid when the number of bidders increases is roughly equal to the fraction of subjects who reduced their bid, we observe that those reducing their bid do so by a greater amount. We also find that $14.6 \%$ of subjects never change their bids when the number of bidders increases, as predicted for instance by Expected Utility and Regret, while $10.55 \%$ of them changed it in a way that cannot be explained by the KR model.

The KR model is related to models of disappointment aversion (henceforth, DA), such as Bell (1985), Loomes and Sugden (1986) and Gul (1991), where outcomes are also evaluated relative to expectations. ${ }^{3}$ Hence, in some of our sessions subjects completed also an individual decision task originally designed by Sprenger (2015) and aimed at distinguishing the KR model from DA models. In particular, the KR model features an "endowment effect for risk" whereby people will be risk averse when their reference point is deterministic, and risk neutral when their reference point is stochastic. By contrast, DA makes no such asymmetric prediction as to the relationship between risk attitudes and reference points, because gambles

\footnotetext{
${ }^{3}$ Unlike the KR model, however, DA models do not define gain/elation and loss/disappointment separately over consumption and money. Yet, if one were to incorporate this feature into DA models then, as shown by Horowitz (2006), in second-price auctions with private values and real objects DA would make predictions qualitatively similar to the ones of the KR model.
} 
are always evaluated relative to a deterministic reference point, that is the gamble's certainty equivalent. Successfully replicating the results in Sprenger (2015), we find evidence of an endowment effect for risk which provides further support for the KR model.

Our paper is related to Banerji and Gupta (2014) who provide evidence in favor of the KR model in an auction-like experiment using the Becker-DeGroot-Marschak (henceforth, BDM) mechanism (Becker, DeGroot and Marschak, 1964). In the BDM mechanism, a single bidder competes against a random bid drawn from a known distribution. If his bid beats the random draw, he wins the prize and pays a price equal to the random draw; if his bid is lower, on the other hand, he loses. It is easy to see that if preferences are standard, this is an incentive-compatible mechanism (i.e., it is optimal to bid one's value for the prize). ${ }^{4}$ Yet, with expectations-based reference-dependent preferences, it is in general not optimal to bid one's value in a BDM auction. Their experimental design exogenously manipulates the expectations-based reference point by assigning subjects to one of two treatments: individuals bid against uniform distributions with supports $\left[0, K_{1}\right]$ in one treatment and $\left[0, K_{2}\right]$ in the other, with $K_{2}>K_{1}$. The KR model predicts that when the prize is a real object, bids in the first treatment will stochastically dominate bids in the second one whereas no significant differences in the distributions of bids should be observed for induced monetary values. Despite these similarities, there are three main differences between our paper and theirs. First, while their experiment has a between-subject design, our experiment has a within-subject design whereby each subject bids for the same prize three times, each time facing a different number of rival bidders. This allows us to perform a direct test of the comparative statics predictions of the KR model. Second, they run their experiment with only one real good (a bar of dark chocolate) whereas we used six different goods, all of which are not perishable and rather expensive. We believe that these better resemble the products that are often sold in many real-world auctions; e.g., internet auctions. Last, their experiment looks at the BDM mechanism which does not posses any element of strategic interaction; while under standard preferences BDM is strategically equivalent to a second-price auction, it is not clear a priori whether the predictions of the KR model would continue to hold in an environment with strategic interaction. Complementing their and other existing studies, our experiment features a strategic setting where subjects' reference points and payoffs depend also on the behavior of their competitors.

Eisenhuth and Grunewald (2018) also carried out a laboratory experiment with real objects and induced values to test the predictions of the KR model in private-value auctions. Differently from us, they find evidence for one-dimensional and against two-dimensional reference dependence. Yet, they use a between-subject design and compare the revenue

\footnotetext{
${ }^{4}$ Due to this property, the BDM auction is popular as a mechanism to "elicit" subjects' willingness to pay and accept (WTP/WTA). However, see Cason and Plott (2014), Mazar et al. (2014), and Tymula et al. (2016) on some of the limitations of the BDM mechanism for consistently eliciting WTP/WTA measures.
} 
between the first-price auction and the all-pay one. Moreover, in their study each subject bid in ten induced-value auctions but only one real-object auction. The differences in the design, therefore, could potentially explain why our findings differ.

More generally, our paper contributes to the recent and growing literature testing the predictions of expectations-based reference dependence. Studying the performance of professional golfers, Pope and Schweitzer (2011) present evidence of reference dependence in putting performance around par on golf holes, which is complemented by further analysis showing a responsiveness of individual golfers' performance to average field performance, a plausible expectation. Similarly, Card and Dahl (2011) document an increase in domestic violence after unexpected NFL losses, which is indicative of a responsiveness to expectations of victory. Crawford and Meng (2011) show that NYC cabdrivers' labor-supply decisions can be rationalized by a model with expectations-based reference dependence in the domains of hours worked and daily earnings. Abeler et al. (2011) present evidence from a real-effort experiment where piece rates are probabilistically replaced with fixed payments. Though the fixed payment should not affect subjects' effort choices under classical preferences, the authors document a responsiveness to the fixed payment which is consistent with expectations-based reference dependence. Building on this design, Gneezy et al. (2017) put the theory to a stricter test by studying whether behavioral responses are monotone in changes in expectations, as predicted by the theory. By documenting a substantial nonmonotonicity in the effort responses, the authors conclude that these fixed payments affect reference points in a more complex way than predicted by expectations-based models. In a modification of a standard endowment effect experiment, Ericson and Fuster (2011) find that individuals with a high experimental probability of being able to exchange are willing to do so with a higher probability than individuals with a low probability of being able to exchange. However, using similar experimental designs, Heffetz and List (2014) and Goette et al. (2014) fail to replicate the results of Ericson and Fuster (2011). Gill and Prowse (2012) experimentally analyze a two-player real-effort sequential game and document a discouragement effect consistent with expectations-based reference dependence. In a laboratory consumption experiment with randomized prices, Karle et al. (2015) document a relationship between consumption choices after the price realization and subsequently measured loss aversion that is consistent with expectations-based reference dependence. Using a similar setup, however, Wenner (2015) fails to find support for expectations-based models. Hence, while the first bulk of evidence, gathered from both the field and the lab, indicated that expectations play an important role in shaping reference points, more recent laboratory studies have documented some clear violations of the model's directional predictions.

Finally, our paper also contributes to the extensive experimental literature on Vickrey auctions with private values. Several studies have found that subjects deviate from the dominant strategy of bidding their values, with overbidding being somewhat more common than 
underbidding (Kagel et al., 1987; Kagel and Levin, 1993; Harstad, 2000; Cooper and Fang, 2008; Garratt et al., 2012; Georganas et al., 2017). By contrast, experimental evidence from the strategically equivalent ascending English auction demonstrates almost immediate convergence to the dominant strategy; see also Li (2017) on the notion of "obviously" strategy-proof mechanisms. Our paper departs from this literature on two main aspects. First, while these papers only considered induced-value auctions, we also analyze auctions with real objects. Second, while the literature's main focus has been on testing whether bidders adopt the dominant strategy of bidding their value, our paper's focus is not on overbidding per se; instead, we test the comparative statics predictions of the KR model about how individual bids are affected by the degree of competition in the auction.

The paper proceeds as follows. Section 2 presents the theoretical framework. Section 3 describes the experimental design and the data. Section 4 presents the results. Section 5 concludes the paper by discussing some limitations of our design as well as possible avenues for future research.

\section{Theoretical Framework}

\subsection{Environment}

Consider a risk-neutral seller auctioning an object to $n \geq 2$ bidders via a second-price sealed-bid auction. Assume bidders have independent private values. ${ }^{5}$ Each bidder's valuation (type) $\theta_{i}$, for $i=1, \ldots, n$, is drawn independently from the same continuous and strictly increasing distribution $H$ which admits a continuous and positive density $h$ everywhere on the support $[0, \bar{\theta}]$.

Bidders have expectations-based reference-dependent preferences as formulated by Köszegi and Rabin (2006). In this formulation, a bidder's utility function has two components:

$$
U\left[c^{g}, c^{p} \mid r^{g}, r^{p}, \theta\right]=\underbrace{\theta c^{g}+c^{p}}_{\text {consumption utility }}+\underbrace{\theta \mu\left(c^{g}-r^{g}\right)+\mu\left(c^{p}-r^{p}\right)}_{\text {gain-loss utility }}
$$

where $c^{g}, r^{g} \in\{0,1\}$ capture the good dimension and $c^{p}, r^{p} \in \mathbb{R}$ capture the money dimension. First, if he wins the auction at price $p$, i.e. $c^{g}=1$ and $c^{p}=-p$, a type- $\theta$ bidder experiences consumption utility $\theta-p$, which represents the classical notion of outcome-based utility. Second, the bidder also derives gain-loss utility from the comparison of his actual consumption to a reference point given by his recent expectations (probabilistic beliefs). The function $\mu$ is assumed to be two-piece linear with a slope of $\eta>0$ for gains and a slope of $\eta \lambda>\eta$ for losses. The parameter $\eta$ captures the relative weight a consumer attaches to gain-loss utility while $\lambda$ is the coefficient of loss aversion. By positing a constant marginal

\footnotetext{
${ }^{5}$ Independence is not crucial for our results, but it simplifies the analysis.
} 
utility from gains and a constant, but larger marginal disutility from losses, this formulation captures prospect theory's (Kahneman and Tversky, 1979; Tversky and Kahneman, 1991) loss aversion, but without its diminishing sensitivity. According to (1), a bidder assesses gains and losses separately over product and money. For instance, if his reference point is that he does not get the product (and thus pays nothing), then he evaluates getting the product and paying for it as a gain in the product dimension and a loss in the money dimension rather than as a single gain or loss. This is consistent with much of the experimental evidence commonly interpreted in terms of loss aversion. ${ }^{6}$

Because in many situations expectations are stochastic, Köszegi and Rabin (2006) extend the utility function in (1) to allow for the reference point to be a pair of probability distributions $\mathbf{H}:=\left(H^{g}, H^{p}\right)$. In this case a bidder's utility can be written as

$$
U\left[\left(c^{g}, c^{p}\right) \mid H^{g}, H^{p}, \theta\right]=\theta c^{g}+c^{p}+\theta \int_{r^{g}} \mu\left(c^{g}-r^{g}\right) d H^{g}+\int_{r^{p}} \mu\left(c^{p}-r^{p}\right) d H^{p}
$$

In words, a bidder compares the realized consumption outcome with each possible outcome in the reference lottery. For example, if he expected to win the auction at price $p$ with probability $q$, then winning the auction feels like a gain of $\eta \theta(1-q)$ in the product dimension and a loss of $-\eta \lambda p(1-q)$ in the money dimension. Similarly, losing the auction results in a loss of $-\eta \lambda \theta q$ and a gain of $\eta p q$. Thus, the weight on the loss (gain) in the overall experience is equal to the probability with which he was expecting to win (lose) the auction.

Each bidder learns his type before bidding and, therefore, maximizes his interim expected utility. If the distribution of the reference point is $\mathbf{H}$ and the distribution of consumption outcomes is $\mathbf{G}:=\left(G^{g}, G^{p}\right)$, a type- $\theta$ bidder's interim expected utility is given by

$$
E U[\mathbf{G} \mid \mathbf{H}, \theta]=\int_{\left\{c^{g}, c^{p}\right\}} U\left[\left(c^{g}, c^{p}\right) \mid H^{g}, H^{p}, \theta\right] d \mathbf{G} .
$$

After placing a bid, a bidder basically faces a lottery between winning or losing the auction and the probabilities and potential payoffs depend on his own as well as the other players' bids. The final outcome is then evaluated with respect to any possible outcome from this lottery as a reference point. As laid out in Köszegi and Rabin (2007), Choice Acclimating Personal Equilibrium $(C P E)$ is the most appropriate solution concept for such decisions under risk when uncertainty is resolved after the decision is made so that the decision maker's strategy determines the distribution of the reference point as well as the distribution of final consumption outcomes; that is, $\mathbf{G}=\mathbf{H}$.

\footnotetext{
${ }^{6}$ This feature is able to explain the endowment effect observed in many laboratory experiments (see Kahneman et al. 1990, 1991). The common explanation of the endowment effect is that owners feel giving up the object as a painful loss that counts more than money they receive in exchange, so that they demand a lot of money for the object. But if gains and losses were defined over the value of the entire transaction, owners would not be more sensitive to giving up the object than to receiving money in exchange.
} 
The following assumption, maintained for the remainder of the paper, guarantees that all bidders participate in the auction for any realization of their own type, and that the equilibrium bidding functions derived in the next sections are strictly increasing and continuous:

\section{Assumption 1 (No dominance of gain-loss utility) $\Lambda \equiv \eta(\lambda-1) \leq 1$.}

This assumption places, for a given $\eta(\lambda)$, an upper bound on $\lambda(\eta)$ and ensures that a bidder's equilibrium expected utility is increasing in his type. What it requires is that the weight a bidder places on expected gain-loss utility does not (strictly) exceed the weight he puts on consumption utility. ${ }^{7}$

Each bidder can place a bid $b \in[0, w]$ where $w$ denotes bidders' symmetric monetary endowments (or budgets). Throughout the paper, we assume that the budget constraint does not bind and we restrict attention to symmetric equilibria in pure and (strictly) monotone strategies. We consider both real-object and induced-value second-price auctions.

\subsection{Real-Object Auctions}

For given bidding strategies of the other players let $F(b)$ denote a bidder's probability of winning the auction with a bid equal to $b$; that is, the probability that the largest of his opponents' bids is lower than $b$. Then, the reference-dependent expected utility of a bidder of type $\theta$ is given by

$$
\begin{aligned}
E U(b, \theta)= & \int_{b(0)}^{b}(\theta-p) d F(p)-\Lambda[1-F(b)] \int_{b(0)}^{b} p d F(p) \\
& -\Lambda \int_{b(0)}^{b} \int_{b(0)}^{p}(p-s) d F(s) d F(p)-\Lambda \theta F(b)[1-F(b)]
\end{aligned}
$$

where $b(0)$ denotes the bid submitted by the lowest type. ${ }^{8}$ The first term on the righthand-side of (3) is standard expected (consumption) utility. The other terms capture expected gain-loss utility and are derived as follows. The second term captures the expected comparison, on the money dimension, between winning the auction and having to pay an expected price of $\int_{b(0)}^{b} p d F(p)$ and losing the auction and saving $\int_{b(0)}^{b} p d F(p)$. The third term reflects the expected comparison, still on the money dimension, between the realized winning

\footnotetext{
${ }^{7}$ Eisenhuth and Grunewald (2018), using data from first-price and all-pay auctions with induced monetary values, obtain an estimate for $\Lambda$ of 0.42 (with a standard error of 0.16 ), which is statistically different from 0 and 1 at all conventional significance levels. Using data from a BDM-like auction for real products (chocolate bars), Banerji and Gupta (2014) obtain an estimate for $\Lambda$ of 0.283 (with a standard error of 0.08), also statistically different from 0 and 1 at all conventional significance levels.

${ }^{8}$ Expression (3) is equivalent to expression (10) in Lange and Ratan (2010). The only difference is that they assume a weight of zero on gains and a positive weight on losses whereas we, following the original formulation of Köszegi and Rabin (2006), posit a positive weight on gains and a larger weight on losses.
} 
price $p$ and all the other prices $s$ the bidder expects to pay with positive probability. The fourth and last term describes the expected gain-loss utility on the good dimension when expecting to win the auction with probability $F(b)$. Finally, notice that risk neutrality is embedded in the model as a special case since $\Lambda=0$ if either $\eta=0$ or $\lambda=1$.

Lange and Ratan (2010) showed that in the unique monotone symmetric equilibrium a bidder of type $\theta$ bids according to the following bidding function:

$$
\begin{aligned}
\beta^{*}(\theta, n)= & \theta\left\{\frac{1-\Lambda\left[1-2 H^{n-1}(\theta)\right]}{1+\Lambda}\right\} \\
& +\frac{2 \Lambda}{(1+\Lambda)^{2}} \int_{0}^{\theta} z\left\{1-\Lambda\left[1-2 H^{n-1}(z)\right]\right\} \exp \left\{\frac{2 \Lambda\left[H^{n-1}(\theta)-H^{n-1}(z)\right]}{1+\Lambda}\right\} d H^{n-1}(z)
\end{aligned}
$$

where $H^{n-1}$ denotes the CDF of the highest order statistic among $n-1$. Indeed, in a symmetric equilibrium $F(b)=H^{n-1}(\theta)$ as a type- $\theta$ bidder expects to win when all his opponents have a type lower than $\theta$. The following proposition compares the loss-averse bid with the risk-neutral one and summarizes some key comparative statics implications.

Proposition 1 Suppose Assumption 1 holds and let $\theta^{m}$ be such that $H^{n-1}\left(\theta^{m}\right)=0.5$. Then $\beta^{*}(\theta, n)$ satisfies the following properties:

(i) $\beta^{*}(\theta, n)$ is continuous and increasing in $\theta$.

(ii) There exists a $\theta^{\prime}>\theta^{m}$ such that $\beta^{*}(\theta, n)<\theta$ for $\theta \in\left[0, \theta^{\prime}\right]$.

(iii) There exists a $\theta^{\prime \prime} \geq \theta^{\prime}$ such that $\beta^{*}(\theta, n) \geq \theta$ for $\theta \in\left[\theta^{\prime \prime}, \bar{\theta}\right]$.

(iv) $\frac{\partial \beta^{*}(\theta, n)}{\partial n}<0$ for all $\theta$ such that $H(\theta)<e^{-\frac{1}{n-1}}$.

(v) The average bid is decreasing in $n$ if $h^{\prime}(\theta) \leq 0$ or if $n$ is large.

Proof. See Appendix A.

Proposition 1 delivers several interesting implications. First, it shows that loss aversion has a "bifurcating" effect whereby bidders with low values bid less than their value whereas the opposite holds for bidders for high values. In particular, loss aversion pushes all bidders who expect to win with less than $50 \%$ probability to underbid. The intuition for this result is straightforward. Recall that when comparing the outcome of winning (resp. losing) the auction to the counterfactual, a loss-averse bidder with type $\theta$ experiences expected gain-loss (dis-)utility proportional to $-\Lambda H^{n-1}(\theta)\left[1-H^{n-1}(\theta)\right]$. Notice that $H^{n-1}(\theta)\left[1-H^{n-1}(\theta)\right]$ is maximized at $H^{n-1}(\theta)=0.5$, which is the point where the bidder faces maximal uncertainty between winning and losing the auction. Bidders who expect to win with less than $50 \%$ probability do not feel attached and therefore bid less aggressively to keep their expectations 
low and mitigate their disappointment if they lose. Next, it is easy to see that a player's equilibrium bid depends on the number of bidders. Under Assumption 1 we have that $\frac{\partial \beta^{*}(\theta, n)}{\partial n}<0$ for all $\theta$ such that $H(\theta)<e^{-\frac{1}{n-1}}$. This (sufficient) condition implies, for example, that if two auctions in this symmetric setting have $n=6$ and $n^{\prime}=12$ bidders respectively, then all bidders whose values fall within the lowest 82 percent of the distribution of values will bid less when the number of bidders is larger. The intuition is as follows. When the number of bidders in the auction increases, ceteris paribus a bidder expects to win with a lower probability. Low-value bidders already expect to win with a rather small probability to begin with so for them losing the auction is not such a big loss in terms of forgoing the object whereas winning the auction would entail quite a painful loss because of the unexpected expenditure; hence, they react to the increase in competition by reducing their bid in order to keep their expectations low and reduce their feelings of loss from not winning the auction (but making a big splash if they do win). On the other hand, high-value bidders expect to win the auction and pay some money with a rather high probability and, therefore, they react to an increase in competition by bidding even more aggressively in order to reduce the chance of experiencing a painful loss from not obtaining the object. In other words, low-value bidders are more sensitive to losses in the money dimension whereas high-value bidders are more sensitive to losses in the object dimension. Finally, the average bid is decreasing in $n$ if the number of bidders is large enough or if high types are rare. When $n$ increases, the probability of winning the auction decreases for all bidders except the one with the highest type. Hence, the measure of types who reduce their bids is increasing with $n$. Figure 1 provides a graphical example to illustrate the comparative statics with respect to the number of bidders. It is easy to see that as $n$ increases, the average bid declines.

\subsection{Induced-Value Auctions}

In an auction with induced monetary values each subject is given a voucher and, if he wins the auction, he can redeem the voucher from the experimenter in exchange of a prespecified dollar amount, say $\$ \theta$. Hence, his intrinsic payoff is $\theta-p$ if he wins the auction at price $p$ and zero otherwise. Crucially, in an auction with induced monetary values there is only one dimension of consumption utility, namely money. Then, the reference-dependent expected utility of a bidder of type $\theta$ is given by

$$
\begin{aligned}
E U_{I V}(b, \theta)= & \int_{b(0)}^{b}(\theta-p) d F(p)-\Lambda[1-F(b)] \int_{b(0)}^{b}(\theta-p) d F(p) \\
& -\Lambda \int_{b(0)}^{b} \int_{b(0)}^{p}(p-s) d F(s) d F(p)
\end{aligned}
$$




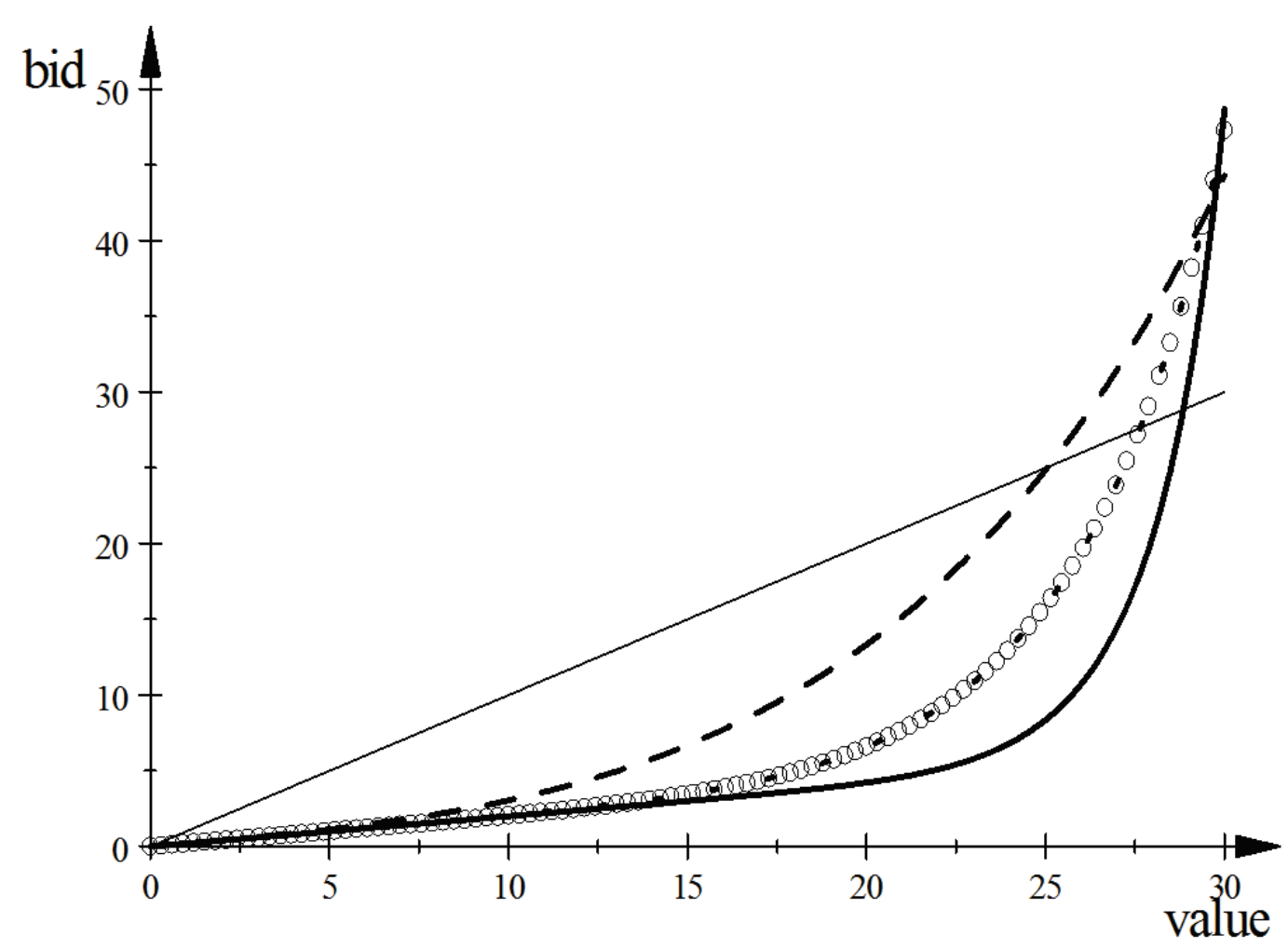

Figure 1: Equilibrium bidding functions for $n=3$ (dashed), 6 (dotted) and 12 (solid) with $\Lambda=2 / 3$ and $\theta$ distributed uniformly on $[0,30]$.

where $b(0)$ denotes the bid submitted by the lowest type. The first term on the righthand-side of (5) represents standard expected (consumption) utility. The second term captures the expected gain-loss utility when comparing the outcome of winning the auction, which yields an expected monetary payoff of $\int_{b(0)}^{b}(\theta-p) d F(p)$, and the outcome of losing the auction, which yields a payoff of 0. Finally, the last term reflects the expected gain-loss utility when comparing winning the auction at price $p$ and winning at all the other prices $s$ which the bidder expects to pay with positive probability.

The bidding strategy of a loss-averse bidder in an induced-value auction is quite different from his strategy in a real-object auction. The reason is that in an auction for a real object the bidder trades off feelings of loss and gain across different dimensions - for example, losing the auction feels like a loss in the product dimension and a gain in money compared to the possibility of winning the auction - and it is not possible for the bidder to eliminate losses on both dimensions simultaneously. In an auction with induced monetary values, instead, losing the auction always feels like a loss compared to the possibility of winning the auction. As shown by Lange and Ratan (2010), in the unique monotone symmetric equilibrium a bidder of type $\theta$ bids according to the following bidding function:

$$
\beta_{I V}^{*}(\theta)=\theta .
$$


Therefore, in induced-value auctions the equilibrium behavior of a loss-averse bidder coincides with that of the "classical" model. Hence, we should observe (even loss-averse) subjects bidding the same amount irrespective of the intensity of competition.

\section{$3 \quad$ Experimental Design}

Each participant in our study took part in twelve auctions: three auctions for each prize and four prizes in total. Specifically, for each prize, a participant took part in: a second-price auction with two competitors $(n=3)$, a second-price auction with five competitors $(n=6)$ and a second-price auction with eleven competitors $(n=12)$. The prize that the participant bid on and the total number of people participating in the auction changed randomly from one auction to another. Manipulating the number of auction participants allowed us to test our main hypothesis: whether the number of bidders in the auction, other things being equal, affects average and individual bids. In each treatment, in the real-object auctions we offered three different products with significant market value (ranging from $\$ 13.95$ to $\$ 49.95$ ); in the induced-value auctions, we offered a money voucher that subjects could redeem for a prespecified dollar amount. Monetary values for the vouchers $\$ x \stackrel{U}{\sim}\{1,2,3, \ldots, 29,30\}$ were drawn independently across subjects. ${ }^{9}$ A subject's value $\$ x$ for the voucher stayed constant throughout the experiment. Subjects' own monetary values were their private information, but the distribution of values was common knowledge. Each participant bid three times for every prize, once for each auction size, for a total of twelve auctions.

In the beginning of each auction, participants were told what prize they were bidding on and how many people in total were participating in the auction (three, six or twelve). After the participant submitted his/her bid, the program automatically moved on to the next auction without providing any feedback on the auction outcome. We did not provide feedback because we wanted to ensure that participants considered each auction to be independent from the others. For each auction, participants were given a $\$ 30$ endowment that they could use to bid in the auction and were allowed to bid any integer amount between $\$ 0$ and $\$ 30$. Their budget in each auction was always $\$ 30$ and the money saved in one auction could not be rolled over to the next one. Therefore, the auctions were independent in terms of budget constraint: whatever happened in one auction had no monetary consequences for the other auctions. Participants submitted their bids privately using a computer interface. Figure 2 shows an example of a decision screen.

To convincingly compare real-object auctions and induced-value auctions, we ran two versions of the experiment. In the first version, which we call "others' prize same" treatment, when participants bid on a prize, they knew that all the other participants in the auction were bidding on the same prize. This is a realistic set up motivated by real-world auctions

\footnotetext{
${ }^{9}$ Throughout the paper the symbol $\$$ denotes Australian dollars (AUD).
} 


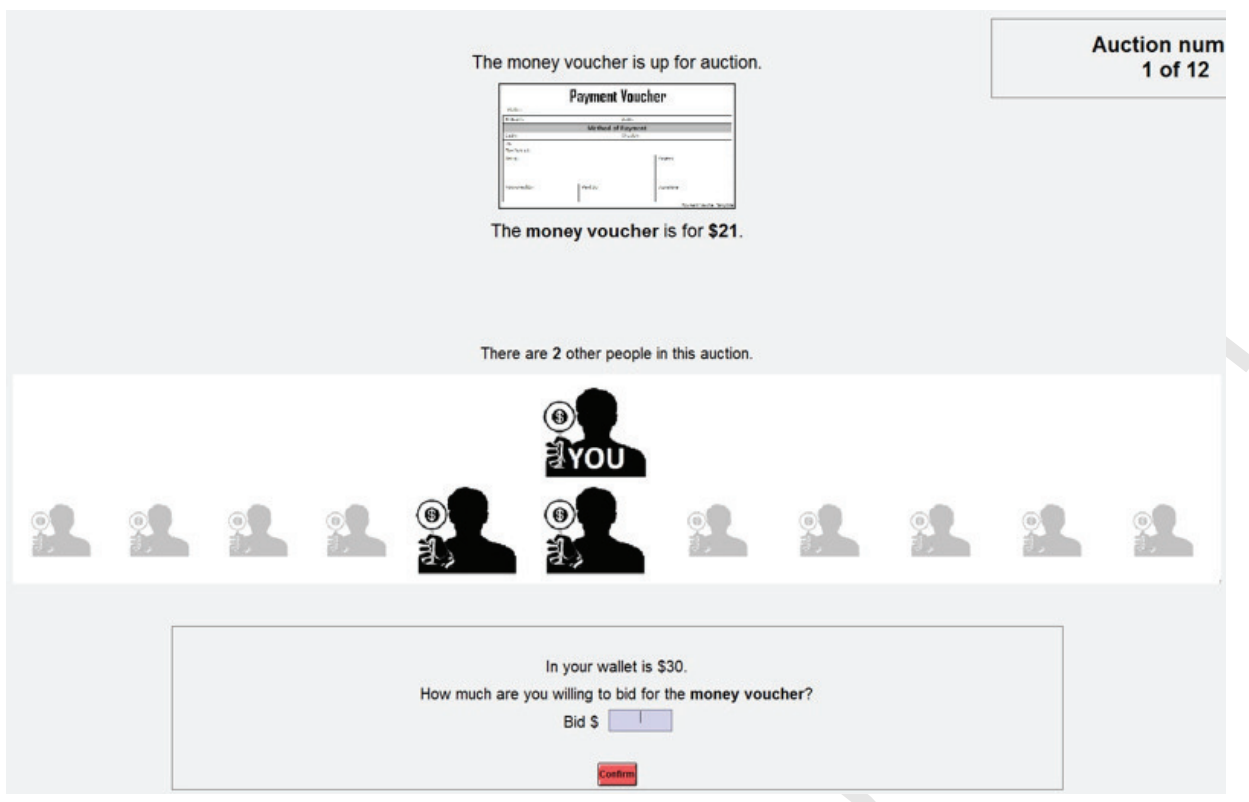

Figure 2: Example of a decision screen. The bidder is bidding for a money voucher valued at $\$ 21$. Three bidders (including the decision-maker) participate in this auction.

where all participants bid on the same object. However, one could object that there is a potential confound in such design because when participants bid on a real object, they knew that all the other participants bid on the same real object with the same market value, but when they bid in an induced-value auction the monetary value of other bidders' voucher was unknown to them. In other words, one could argue that the values in the induced-value auctions were independent while the values in real-object auctions were not, thereby creating a confound. ${ }^{10}$ We addressed this concern with a perhaps less realistic treatment that we call "others' prize unknown". In this treatment, when participants bid on a real object they knew that others were bidding on a real object as well, but they did not know which one. Therefore, in the "others' prize unknown" treatment a participant never knew the (market or induced) value of the prize that other participants were bidding on, ensuring that in both induced-value and real-object auction the values are independent. ${ }^{11}$

To cater to different tastes, we included three different real-object prizes in each treatment. In the "others' prize same" treatment we used: a voucher for two cinema tickets, a Logitech Boombox, and a University of Sydney hoodie. ${ }^{12}$ In the "others' prize unknown" treatment we used: a voucher for two cinema tickets, a University of Sydney t-shirt and a University of Sydney mug. ${ }^{13}$ As people who are not interested in buying a particular good

\footnotetext{
${ }^{10}$ We thank a referee and an advisory editor for pointing this out to us.

${ }^{11}$ Notice that the fact that other participants might be bidding on a different item does not affect a participant's bidding incentives under Expected Utility Theory (as well as Regret Theory, Level-k, etc.); hence, it is still a (weakly) dominant strategy for a bidder to bid his/her value, no matter how many competitors $\mathrm{s} /$ he faces.

${ }^{12} \mathrm{At}$ the time of the experiment, the market prices of the products were $\$ 39, \$ 49.95$, and $\$ 39.95$ respectively.

${ }^{13} \mathrm{At}$ the time of the experiment, the market prices of the products were $\$ 42, \$ 24.95$, and $\$ 13.95$ respectively.
} 
would simply bid $\$ 0$, and therefore be insensitive to the number of people in the auction, we included three different real-object prizes with the intent to increase the chance that each participant would find at least one of the goods desirable. Two prizes remain the same between the treatments while two were replaced due to the lack of availability in the store.

We ran a total of sixteen sessions - eight in each treatment. Twelve participants took part in each session resulting in a total of twenty-eight auctions run in each individual session: four auctions with all twelve participants (one for each prize), eight auctions with six participants (two for each prize) and sixteen auctions with three participants (four for each prize). Groups of participants in each auction were selected at random and participants did not know the identity of people whom they were bidding against. The order of the auctions was randomized independently for every participant. Participants knew that at the end of the experiment one of the twenty-eight auctions that took place during the session would be selected for payment (we call this the "payout auction"). Subjects who did not participate in this auction received nothing. Subjects who participated in the payout auction but did not win the auction, received the $\$ 30$ endowment. ${ }^{14}$ The participant with the highest bid in the payout auction received the prize and paid for it a price equal to the second-highest bid, leaving him/her with $\$ 30$ minus the second highest bid in cash, plus the prize.

After the auction task was over, subjects completed an independent individual decisionmaking task with a between-subject design. This task followed the same procedures as in Sprenger (2015) who designed an experiment aimed at distinguishing the KR model from models of Disappointment Aversion (Bell, 1985; Loomes and Sudgen, 1986; Gul, 1991). We present the description of the task and the results that are in line with the original paper in Appendix B. This task was included only in the "others' prize same" treatment.

After completing the tasks, subjects answered a short questionnaire (for questions see Appendix F). The total earnings for participation in the study were given by the sum of a $\$ 10$ show up fee and earnings in the auction task. In the "others' prize same" treatment, participants also received earnings from the individual decision-making task. ${ }^{15}$

\footnotetext{
${ }^{14}$ It it important to highlight that a losing bidder in the payout auction still received the $\$ 30$ endowment. We decided to do so, and stressed this feature of the payment rule during the instructions-reading phase of the experiment, because we wanted subjects to realize that winning (resp. losing) the auction implies a loss of money (resp. product) and a gain of product (resp. money).

${ }^{15}$ In both the auction task and the individual decision-making task, subjects were randomly paid for one of their choices. This random-lottery incentive mechanism, which is widely used in experimental economics, introduces a compound lottery in the decision environment. While this is inconsequential for a decision-maker under standard expected utility, because of the reduction of compound lotteries property, the randomization introduces some further complications in the KR framework as it creates a potential link between choices and reference points across tasks. Yet, the random-lottery incentive mechanism is innocuous also in the KR framework under "narrow framing/bracketing "whereby subjects consider each decision in isolation (see Tversky and Kahneman, 1981 and Rabin and Weizsäcker, 2009). While we cannot ensure that our subjects did indeed consider each auction in isolation, we notice that the order of auctions was random across subjects and no outcome was revealed until the end of the experiment. As for the individual decision-making task, in a series of experiments involving decisions over risky prospects, Starmer and Sudgen (1991) and Cubitt et al. (1998) provide evidence that in practice subjects treat these decisions effectively in isolation.
} 
Before completing each task, participants received detailed instructions (available in Appendix D). To make sure that the rules of the second-price auction were clear to everybody, each participant had to answer detailed comprehension questions before starting the task. If a participant failed a question (or part of it), the experimenter explained the task verbally and gave the participant a second set of comprehension questions to complete. Most participants answered all the questions correctly at the first attempt. All of them answered them correctly within two attempts. Comprehension questions are available in Appendix E.

A total of 192 subjects (83 males; average age: $23+/-4.24 \mathrm{SD}$ ) took part in the study, which took place in the experimental laboratory of the University of Sydney. Data for "others' prize same" treatment was collected between May and June 2015 and data for "others' prize unknown" treatment was collected in April 2018. The protocol was approved by the Human Ethics Research Committee at the University of Sydney. The study was implemented using ZTree (Fischbacher, 2007) and subjects were recruited via ORSEE (Greiner, 2015).

\section{Results}

Given the predictions of our theoretical framework, in this section we test two main hypotheses about participants' bids:

Hypothesis 1 Bids in real-object auctions depend on the number of bidders. Specifically, the average bid declines in the number of auction participants.

Hypothesis 2 Bids in induced-value auctions are not influenced by the number of bidders.

\subsection{Summary Statistics}

As there were no differences in design between the two treatments for the induced-value auctions, we combine data from all these auctions together for the ease of presentation and discussion. We begin by providing some summary statistics on participants' bids in Table 1.

The actual participation in the auctions was high, with participants biding sizable amounts on each prize and rarely bidding $\$ 0$. Out of 288 bids for each good, only 9, 11, 8, 10, 13 and 14 were equal to $\$ 0$ for movie tickets in "others' prize same", boombox, hoodie, movie tickets in "others' prize unknown", t-shirt and mug, respectively; moreover, only 24 out of 576 bids on the money voucher were equal to $\$ 0$. There was substantial variation in individual bids on each of the items suggesting that different people assigned different value to each good.

To assess whether subjects changed their bid for the same prize, for each participant we computed the standard deviation of his/her bid separately for each prize. This gives us a total of seven standard deviation indexes for a participant, one for each prize (see the 
Table 1: Summary statistics of bids for each good

\begin{tabular}{lccccc}
\hline & mean & min & max & sample SD & within individual SD \\
\hline others' prize same treatment & \\
movie & 15.72 & 0 & 30 & 9.62 & 2.09 \\
boombox & 19.22 & 0 & 30 & 10.51 & 2.88 \\
hoodie & 17.76 & 0 & 30 & 10.68 & 2.36 \\
& & others' & prize & unknown treatment \\
movie & 18.36 & 0 & 30 & 9.86 & 2.44 \\
t-shirt & 14.52 & 0 & 30 & 10.28 & 2.16 \\
mug & 10.71 & 0 & 30 & 9.80 & 1.94 \\
& & & & & \\
voucher & 15.43 & 0 & 30 & 10.01 & 1.67 \\
\hline
\end{tabular}

averages in last column in Table 1). If participants bid always the same amount, this index should be equal to zero, implying that auction size did not affect bids. To the contrary, the standard deviation of individual bids for a particular prize is on average equal to 2.15 . It is the smallest for the money voucher (1.67) and largest for boombox (2.88).

For each prize, Table 7 and 8 in Appendix C summarize the self-reported familiarity, ownership, desire to buy, feeling of being budget constrained when bidding, willingness to pay and intended use statistics that were obtained in the post-experimental questionnaire.

\subsection{Real-Object Auctions Results}

To establish whether the observed within-subject and within-good variation in bids is driven by the number of participants in the auction, we first calculated average bids for each good and each auction size (Table 2). In line with Hypothesis 1, average bids for all real objects decline as the number of participants in the auction increases from three to twelve, on average by $\$ 1.10$. Similarly, they also decline as the number of participants increases from six to twelve, on average by $\$ 0.80$, for all goods except movie tickets in "others' prize unknown". Notice that instead the bids on the money voucher change by less than $\$ 0.01$ when the number of participants increases from three to twelve and by $\$ 0.35$ when the number of participants increases from six to twelve. For movie tickets, boombox and mug, the average bid also declines when the number of participants increases from three to six.

To verify whether the relationship between bids and number of auction participants is significant, in our estimation we need to account for the fact that each individual may value each good differently. We do this in two different ways, each leading to the same qualitative conclusions. In the main text, we present the results from a random effects model and in 
Table 2: Mean bid by good and auction size

\begin{tabular}{lccc}
\hline & $\mathbf{3}$ participants & $\mathbf{6}$ participants & $\mathbf{1 2}$ participants \\
\hline \multirow{4}{*}{ others' } & prize same treatment \\
movie & 16.10 & 15.93 & 15.12 \\
boombox & 19.70 & 19.32 & 18.64 \\
hoodie & 18.04 & 18.21 & 17.02 \\
& others' & prize unknown treatment \\
movie & 18.95 & 17.98 & 18.14 \\
t-shirt & 14.85 & 14.90 & 13.82 \\
mug & 11.43 & 10.93 & 9.76 \\
& & & 15.31 \\
voucher & 15.32 & 15.66 & \\
\hline
\end{tabular}

Appendix C we report the results from the regressions with individual-good fixed effects. ${ }^{16}$

Pooling all prizes together, we find that bids are significantly lower when there are three or six participants in the auction as compared to auctions with twelve participants (Table 3). Importantly, the effect is stronger when we focus only on real-good auctions and it disappears when we focus only on induced-value auctions.

To gain more insight and to see whether the results from the "pooled" regressions hold also at the individual good level, in Table 4 we regressed individual bids on auction size dummy variables separately for each good. Consistent with Hypothesis 1, individuals bid significantly more for movie tickets in the "others' prize same" treatment, hoodie, t-shirt and mug in 3-bidder auctions compared to 12-bidder ones. While the coefficient for boombox is among the highest, it misses significance. This may be related to three possible explanations that emerge from our post-experimental questionnaire: (i) subjects were least familiar with this product and this might introduce noise in the bids, (ii) a high percentage of subjects indicated that they felt budget-constrained when bidding on the boombox and, therefore, by capping bids at $\$ 30$ we precluded ourselves from seeing the effect for some of the participants, and (iii) a high percentage of subjects stated they would resell the boombox if purchased; if bidders plan to resell the prize, the KR model predicts that they should treat the good as cash and so there should be no effect of the number of participants on bids.

Similarly, the coefficient on the movie tickets in the "others' prize unknown" treatment is not significant. It is hard to speculate why this may be the case based on the self-reported

\footnotetext{
${ }^{16}$ According to the Hausman test, the error term and the regressors are not correlated and hence the random effects model is more appropriate to analyze our data $\left(\chi^{2}=0.00, p=1.00\right)$. There are however significant differences in bids across individual-good pairs, indicating we should use random effects rather than a simple OLS regression $\left(\chi^{2}=1716.13, p<0.001\right.$, Breusch-Pagan Lagrange multiplier test).
} 
Table 3: Effect of auction size on bids. 3 participants (6 participants) is an indicator variable equal to one when the participant is bidding in an auction with 3 (6) bidders. The reference category is auction with 12 bidders. Subject-good random effects are included. Standard errors are reported in parentheses. ${ }^{*} p<.10,{ }^{* *} p<.05,{ }^{* * *} p<.01$.

\begin{tabular}{lrrr}
\hline & all prizes & real goods & money voucher \\
\hline 3 participants & $0.82^{* * *}$ & $1.10^{* * *}$ & 0.01 \\
& $(0.20)$ & $(0.24)$ & $(0.33)$ \\
6 participants & $0.68^{* * *}$ & $0.80^{* * *}$ & 0.35 \\
& $(0.20)$ & $(0.24)$ & $(0.33)$ \\
constant & $15.39^{* * *}$ & $15.42^{* * *}$ & $15.31^{* * *}$ \\
& $(0.37)$ & $(0.44)$ & $(0.72)$ \\
\hline No. of obs & 2304 & 1728 & 576 \\
\hline
\end{tabular}

measures in Tables 7 and 8. However, we note that the price of the movie tickets increased from $\$ 39$ to $\$ 42$ in the time between the data from the two different treatments were collected, making the movie tickets go from being the least expensive product in the "others' prize same" treatment to being the most expensive one in the "others' prize unknown" treatment. Hence, in both treatments we fail to detect a significant effect for the most expensive and highest valued product. One reason for this might be a form of context-dependent reference effects, not captured by the KR model, whereby bidders would not be negatively affected by an increase in the intensity of competition for the good that they perceive to be more valuable. An alternative explanation, more in line with the KR model, is that high-value bidders might actually increase their bids in response to an increase in the intensity of competition. Therefore, while the average bid should still decline with number of bidders, the presence of high-value bidders who increase their bids might weaken the overall effect. This mechanism is especially relevant for the "others' prize unknown" treatment where a subject bidding on the most expensive/valuable item (the movie tickets) is more likely to be a high-value bidder, and hence expects to win with a rather high chance, since his/her competitors are more likely to be bidding on a less expensive/valuable item. Finally, we notice that subjects bid significantly more for hoodie, t-shirt and mug in the auction with six bidders than in the auction with twelve bidders.

In Appendix $\mathrm{C}$, we present additional analysis and robustness checks. We briefly discuss these here. A substantial fraction of bids (17\%) in our sample were equal to the maximum possible bid (\$30), suggesting that some subjects may have felt budget constrained. Thus, to account for the censored nature of the data we estimated a Tobit random effects model. The results (see Table 10) are qualitatively similar to those in Table 4. Moreover, we find an even stronger, negative effect of competition in real-object auctions if we exclude those 
Table 4: Effect of auction size on bids. 3 participants (6 participants) is an indicator variable equal to one when the participant is bidding in an auction with 3 (6) bidders. The reference category is auction with 12 bidders. Subject-good random effects are included. Standard errors are reported in parentheses. ${ }^{*} p<.10,{ }^{* *} p<.05,{ }^{* * *} p<.01$.

\begin{tabular}{lrrr|rrr|r}
\hline & \multicolumn{3}{c|}{ other's prize same } & \multicolumn{2}{c|}{ others' prize unknown } & \\
& movie & boombox & hoodie & movie & t-shirt & \multicolumn{1}{c}{ mug } & voucher \\
\hline 3 participants & $0.99^{* *}$ & 1.06 & $1.02^{*}$ & 0.81 & $1.03^{*}$ & $1.67^{* * *}$ & 0.01 \\
& $(0.50)$ & $(0.71)$ & $(0.57)$ & $(0.63)$ & $(0.57)$ & $(0.45)$ & $(0.33)$ \\
6 participants & 0.81 & 0.68 & $1.19^{* *}$ & -0.16 & $1.07^{*}$ & $1.17^{* * *}$ & 0.35 \\
& $(0.50)$ & $(0.71)$ & $(0.57)$ & $(0.63)$ & $(0.57)$ & $(0.45)$ & $(0.33)$ \\
constant & $15.11^{* * *}$ & $18.64^{* * *}$ & $17.02^{* * *}$ & $18.14^{* * *}$ & $13.82^{* * *}$ & $9.76^{* * *}$ & $15.31^{* * *}$ \\
& $(0.98)$ & $(1.08)$ & $(1.09)$ & $(1.01)$ & $(1.05)$ & $(1.00)$ & $(0.72)$ \\
\hline No. of obs & 288 & 288 & 288 & 288 & 288 & 288 & 576 \\
\hline
\end{tabular}

participants who overbid in induced-value ones (see Table 11), suggesting that the KR model describes better the behavior of more rational participants. Removing participants who reported to be budget constrained eliminates significance for all goods except the mug (see Table 12); we suspect this may be driven by the correlation between reporting to be constrained and having a high desire/being a serious bidder for the prize (desire for constrained was 4.85 vs. 3.48 for not constrained, $p<0.001)$. Finally, if we exclude participants who indicated that they would resell the prize (see Table 13), the estimated coefficients are similar to those in Table 4, but with some loss in significance. Hence, we conclude that overall, at the aggregate level, our experimental evidence supports Hypothesis 1:

Result 1 Participants on average bid less in real-object auctions as the number of auction participants increases.

We end this section by remarking that our aggregate findings cannot be rationalized by alternative models of choice under uncertainty, like regret or ambiguity aversion, nor by a model of less-than-fully-rational bidders like level-k. Furthermore, the two leading hypotheses that have been put forward to rationalize overbidding in most experimental second-price auctions, the spite hypothesis and the "joy of winning" hypothesis, cannot explain our findings either. Indeed, while these hypotheses predict that bidders would bid more than their intrinsic value in a second-price auction, the amount of overbidding is independent of the number of bidders in the auction. Moreover, neither spite nor "joy of winning" would predict a difference between real-object auctions and induced-value ones. 

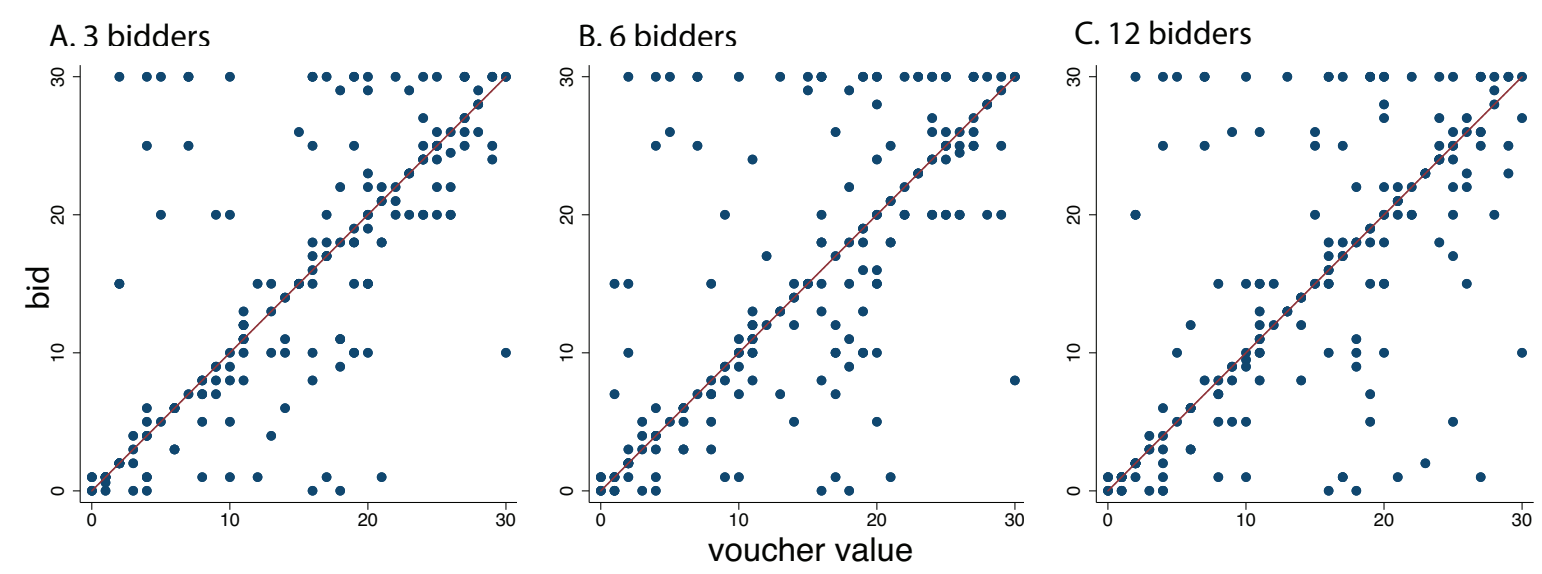

Figure 3: Individual bids for money vouchers plotted against the induced voucher value.

\subsection{Induced-Value Auctions Results}

According to Hypothesis 2, the number of auction participants should not have a significant effect on bids in the induced-value auctions. In line with this hypothesis, the standard deviation in individual bids is the smallest for the money voucher (last column in Table 1). In addition, the mean bid for the money voucher in our sample does not significantly change as the number of bidders increases (Table 2, Table 3, and Table 4).

Regressing bids on the induced values we find that the correlation between the two is highly significant. The coefficient on the voucher value is equal to 0.82 (resp. 0.78 and 0.74 ) in auctions with three (resp. six and twelve) bidders, all with $p<0.001$. Figure 3 plots individuals' bids against the value of their vouchers for each auction size. If subjects bid exactly the value of their money voucher, all bids should fall on the 45-degree lines. However, this is not what we observe. Averaging across all auction sizes, we find that $33.68 \%$ of the bids were equal to the voucher value, $35.34 \%$ of bids were below the voucher value and the remaining $31.08 \%$ were above it. Our fraction of value-bidding is in line with previous experimental findings, but we observe more underbidding than overbidding. For instance, Kagel and Levin (1993) found 27\% of value-bidding, $5.7 \%$ of underbidding and $67.2 \%$ of overbidding. In Cooper and Fang (2008) and Garratt et al. (2012) the same figures were: $44 \%, 16 \%$ and $40 \%$, and $21.2 \%, 41.3 \%$ and $37.5 \%$, respectively.

Overall, we conclude that the experimental evidence supports Hypothesis 2:

Result 2 The number of participants does not affect bids in induced-value auctions.

\subsection{Individual Level Results}

Now we turn to test whether our hypotheses hold also at the individual level. We find significant heterogeneity in how subjects responded to changes in the number of bidders in the auction. On average, participants changed their bid at least once for 2.41 prizes (out 
of 4) as the number of auction participants changed. Moreover, $14.58 \%$ of the participants never changed their bid, $13.02 \%$ changed it for one prize, $16.67 \%$ for two prizes, $28.65 \%$ for three prizes and $27.08 \%$ for all four prizes (including the money voucher). In line with Hypothesis 2, participants changed their bids the least often for the money voucher.

Table 5 lists for each good how many subjects decreased, increased or did not change their bids as the auction's size changed. For example, considering auctions for the movie tickets in the "others' prize same" treatment, from Table 5 we see that 31 (resp. 26, 39) participants decreased (resp. increased, did not change) their bid in an auction with twelve bidders as compared to their bid in an auction for the same product with only three bidders. Focusing on bid changes between 3-bidder and 12-bidder auctions, we find that $60 \%$ of the subjects did not change their bid for the money voucher between 3-bidder and 12-bidder auctions. The fraction of subjects who bid the same amount of money in 3-bidder and 12bidder auctions for movie tickets in "others' prize same", boombox, hoodie, movie tickets in "others' prize unknown", t-shirt, and mug is significantly lower (41\%, 40\%, 49\%, 43\%, 53\% and $44 \%$, respectively). Similar patterns were observed when the auction size changed from three to six and from six to twelve.

Table 5: Number of participants that increase $(\uparrow)$, decrease $(\downarrow)$ or keep their bid constant (-) as number of participants changes

\begin{tabular}{|c|c|c|c|c|c|c|c|c|c|}
\hline & $\begin{array}{c}3 \text { to } 12 \\
\downarrow\end{array}$ & & & $\begin{array}{c}3 \text { to } 6 \\
\downarrow\end{array}$ & $\uparrow$ & - & $\begin{array}{c}6 \text { to } 12 \\
\downarrow\end{array}$ & $\uparrow$ & - \\
\hline \multicolumn{10}{|c|}{ others' prize same treatment } \\
\hline movie & 31 & 26 & 39 & 26 & 22 & 48 & 25 & 23 & 48 \\
\hline boombox & 26 & 32 & 38 & 22 & 31 & 43 & 24 & 23 & 49 \\
\hline hoodie & 23 & 26 & 47 & 19 & 26 & 51 & 22 & 24 & 50 \\
\hline \multicolumn{10}{|c|}{ others' prize unknown treatment } \\
\hline movie & 26 & 29 & 41 & 25 & 22 & 49 & 20 & 28 & 48 \\
\hline tshirt & 24 & 21 & 51 & 22 & 23 & 51 & 20 & 19 & 57 \\
\hline mug & 36 & 18 & 42 & 21 & 19 & 56 & 28 & 16 & 52 \\
\hline voucher & 32 & 44 & 116 & 33 & 43 & 116 & 40 & 45 & 107 \\
\hline all real goods & 166 & 152 & 258 & 135 & 143 & 298 & 139 & 133 & 304 \\
\hline
\end{tabular}

Interestingly, and seemingly contrary to our hypothesis, not all participants decreased their bids as the number of bidders in the auction increased. It is clear from Table 5 that the number of people who decrease their bid as competition in the auction increases is roughly comparable to the number of those who do the opposite. The proportion of those decreasing their bid as the number of bidders increases is higher if we treat small changes in bids as no change (see Table 14 in Appendix C). What explains our aggregate results in the preceding section is that on average the increases in bids were much smaller than 
the decreases in terms of dollar amounts (see Table 6). A series of one-sided t-tests reveals that the differences between bids in 12-bidder and 3-bidder auctions are significantly lower than zero for essentially all real goods, indicating that when the prize was a real object subjects bid significantly less in 12-bidder auctions than in 3-bidder auctions. ${ }^{17}$ We find similar significant effects for a change from six to twelve bidders in auctions for movie tickets in "others' prize same", hoodie, t-shirt, and mug. By contrast, the difference between bids in induced-value auctions of different sizes is never significantly different from zero.

Table 6: Changes in bids (in AUD) as the number of auction participants changes, conditional on participants' decreasing $(\downarrow)$ or increasing $(\uparrow)$ their bid. Average is the sample average. ${ }^{*} p<0.1,{ }^{* *} p<0.05,{ }^{* * *} p<0.01$ in a one sided t-test testing whether the average difference between the bids is smaller than zero

\begin{tabular}{|c|c|c|c|c|c|c|c|c|c|}
\hline & $\begin{array}{c}3 \text { to } 12 \\
\downarrow\end{array}$ & $\uparrow$ & average & $\begin{array}{c}3 \text { to } 6 \\
\downarrow\end{array}$ & & average & $\begin{array}{c}6 \text { to } 12 \\
\downarrow\end{array}$ & $\uparrow$ & average \\
\hline \multicolumn{10}{|c|}{ others' prize same treatment } \\
\hline movie & -6.58 & 4.19 & $-0.99 *$ & -3.54 & 3.41 & -0.18 & -6.68 & 3.87 & $-0.81^{*}$ \\
\hline boombox & -9.08 & 4.20 & $-1.06^{*}$ & -7.91 & 4.45 & -0.38 & -8 & 5.5 & -0.68 \\
\hline hoodie & -9.70 & 4.81 & $-1.02^{*}$ & -4.15 & 3.67 & 0.17 & -9.71 & 4.13 & $-1.19 * *$ \\
\hline \multicolumn{10}{|c|}{ others' prize unknown treatment } \\
\hline movie & -7.29 & 3.86 & -0.81 & -6.80 & 3.50 & $-0.97^{* *}$ & -7.63 & 6.00 & 0.16 \\
\hline t-shirt & -7.79 & 4.19 & $-1.03 * * *$ & -4.82 & 4.78 & -0.04 & -9.20 & 4.26 & $-1.07^{* *}$ \\
\hline mug & -6.03 & 3.14 & $-1.67 * * *$ & -4.95 & 2.95 & $-0.50^{*}$ & -6.21 & 3.84 & $-1.17^{* *}$ \\
\hline voucher & -6.30 & 4.55 & -0.00 & -3.84 & 4.49 & 0.35 & -6.38 & 4.16 & -0.35 \\
\hline
\end{tabular}

Another prediction of the KR model, as illustrated in Figure 1, is that for participants with the highest valuations, we should observe a smaller decline (or an increase) in bids as the number of participants in the auction increases. Thus, we would expect that if we excluded these participants from our analysis, the decline in the average bid should be even stronger. As we do not observe our participants' true valuations, we decided to instead approximate them by the average bid within an individual-good pair. Since our theoretical framework is symmetric and equilibrium bids are strictly increasing in valuations, the participants submitting the highest bids should be the ones with the highest valuations. In the "others' prize same" treatment, we excluded the top $10 \%$ of bidders for each good (that is, bidders with average bid equal or larger than $\$ 28.67$ for movie tickets, and $\$ 30$ for boombox and hoodie). In the "others' prize unknown" treatment, for movie tickets, T-shirt and mug we excluded participant-good pairs where the average bid was above $\$ 29.67$ (which represents the $90^{t h}$ percentile for bids on these goods taken together). For the money voucher, the $90^{t h}$

\footnotetext{
${ }^{17} p=0.1002$ for movie tickets in the "others' prize unkwnon" treatment.
} 
percentile was at $\$ 29$. We repeated the analysis presented in Table 4 excluding the top $10 \%$ bidders and found that the results are indeed stronger (see Table 15 in Appendix C).

Finally, we notice that some of the patterns that we observe at the individual level cannot be explained with the KR model. Specifically, under KR, if for the same prize a participant bid less in a 6-bidder auction than in a 3-bidder auction, then this participant should also bid less in a 12-bidder auction than in a 6-bidder auction. We find that the bids of $10.55 \%$ of the participants violate this prediction and are therefore not consistent with the KR model.

\section{Discussion and Conclusion}

We presented results from two laboratory experiments with a within-subject design, aimed at testing a distinctive comparative static prediction of the KR model in second-price auctions. Our results are broadly consistent with the KR model. In real-object auctions, we find that subjects' bids are affected by the number of competitors and, on average, they decline with the intensity of competition. In induced-value auctions, instead, bids are unaffected by the intensity of competition. These results also show that people behave differently in auctions for real objects than in auctions with induced monetary values, casting some doubts on the extent to which conclusions drawn from laboratory auctions with induced valuations can be extended to real-object auctions in the field. We conclude the paper by discussing some limitations of our design and possible directions for future research.

As the KR model makes different predictions for real-object auctions vs. induced-value ones, we had subjects participating in both. While conducting real-object auctions in the laboratory opens the door to considering many new interesting questions, it also has some drawbacks. In particular, we cannot pin down what subjects' intrinsic value for a product is. Indeed, as argued by Banerji and Gupta (2014) and others, estimates of WTP that are derived using the conventional BDM mechanism are likely to be significantly biased if agents are loss-averse. As it is not possible to directly observe (and control for) subjects' intrinsic values, one possible concern in our experiment is the possibility that in real-object auctions subjects have interdependent or common values. We addressed this potential confound with our "others' prize unknown" treatment whereby, when bidding in a real-object auction, a subject knew that the other participants were bidding on a real object as well, but did not know which one. This design makes the real-object auctions as analogous as possible to the induced-value ones since subjects do not bid on the same good, but have probabilistic beliefs about which goods their competitors are bidding on, just like in the induced-value auctions a bidder knows the value of his/her voucher, but only knows the distribution from which the values of his/her competitors' vouchers are drawn. Furthermore, we notice that the interdependent or common-value model usually applies to goods whose objective quality or value is uncertain and for which bidders have access to different information. In our 
experiment, most subjects were highly familiar with the products and they all had the same opportunity to inspect them before the auctions began.

Another possible concern when using real goods is the possibility of resale. We could have avoided this issue by auctioning off some immediate consumption good, like a chocolate bar or a sandwich. However, we chose to use durable, somewhat expensive items to cater to different tastes and also to increase the chance that subjects in our experiment would find at least one of the items to be appealing. Moreover, we wanted to use products that can be reasonably found in actual auctions in the field. If subjects were only interested in the items we selected for the purpose of reselling them, then they should have bid for them like they bid for money vouchers. The fact that the observed bidding behavior in real-object auctions was significantly different than the bidding behavior in the induced-value auctions suggests that resale is not a major concern for our experiment.

Besides providing support for the KR model, our results have potentially interesting implications for auction design. Bulow and Klemperer (1996) showed that if bidders have standard preferences, an auction with $n+1$ bidders and no reserve price yields a higher expected revenue than an auction with $n$ bidders and an optimally set reserve price. Hence, when facing the choice between introducing a reserve price or inviting an additional bidder into the auction, a revenue-maximizing seller should always pick the latter. Our results, however, suggest that this might not be the case if bidders are expectations-based lossaverse, as increasing competition in the auction might induce (some) bidders to bid less aggressively. Notice though that our results show that average bids decline with the intensity of competition; yet, the effect on the seller's revenue depends on how competition affects the second-highest bid. Analyzing how reserve prices and varying the number of bidders might affect revenue when bidders are loss-averse is an interesting question left for future research. 


\section{References}

[1] Abeler, J., A. Falk, L. Goette and D. Huffman (2011), "Reference Points and Effort Provision" American Economic Review, 101(2), 470-492.

[2] BanerJi, A. and N. Gupta (2014), "Detection, Identification and Estimation of Loss Aversion: Evidence from an Auction Experiment" American Economic Journal: Microeconomics, 6(1), 91-133.

[3] Becker, G., M. Degroot and J. Marschak (1964), "Measuring Utility by a SingleResponse Sequential Method"Behavioral Science, 9(3), 226-232.

[4] BeLL, D. (1985), "Disappointment in Decision Making under Uncertainty" Operations Research, 33(1), 1-27.

[5] Bulow, J., and P. Klemperer (1996), "Auctions Versus Negotiations" American Economic Review 86(1), 180-194.

[6] Card, D., and G. Dahl (2011), "Family Violence and Football: The Effect of Unexpected Emotional Cues on Violent Behavior" Quarterly Journal of Economics 126(1), 103-143.

[7] Cason, T., and C. Plott (2014), "Misconceptions and Game Form Recognition: Challenges to Theories of Revealed Preference and Framing" Journal of Political Economy 122(6), 1235-1270.

[8] Chen, Y., P. KatuščÁK and E. Ozdenoren (2007) "Sealed Bid Auctions with Ambiguity: Theory and Experiments" Journal of Economic Theory, 136(1), 513-535.

[9] Cooper, D. and H. Fang (2008), "Understanding Overbidding in Second Price Auctions: An Experimental Study" Economic Journal, 118(532), 1572-1595.

[10] Crawford, V. and N. Iriberri (2007) "Level-k Auctions: Can a Nonequilibrium Model of Strategic Thinking Explain the Winner's Curse and Overbidding in PrivateValue Auctions?" Econometrica, 75(6), 1721-1770.

[11] Crawford, V. and J.J. Meng (2011) "New York City Cabdrivers' Labor Supply Revisited: Reference-dependent Preferences with Rational Expectations Targets for Hours and Income" American Economic Review, 101(5), 1912-1932.

[12] Cubitt, R., C. Starmer and R. Sudgen (1998), "On the Validity of the Random Lottery Incentive System" Experimental Economics, 1(2), 115-131. 
[13] Eisenhuth, R. (2018), "Reference Dependent Mechanism Design" forthcoming in Economic Theory Bulletin.

[14] Eisenhuth, R. and M.Grunewald (2018), "Auctions with Loss Averse Bidders" forthcoming in International Journal of Economic Theory.

[15] Ericson Marzilli, K.M. and A. Fuster (2011), "Expectations as Endowments: Evidence on Reference-Dependent Preferences from Exchange and Valuation Experiments" Quarterly Journal of Economics, 126(4), 1879-1907.

[16] Fischbacher, U. (2007), “z-Tree: Zurich Toolbox for Ready-made Economic Experiments " Experimental Economics, 10(2), 171-178.

[17] Garratt, R., M. Walker and J. Wooders (2012), "Behavior in Second-price Auctions by Highly Experienced eBay Buyers and Sellers" Experimental Economics, $15(1), 44-57$.

[18] Georganas, S., D. Levin and P. McGee (2017), "Optimistic Irrationality and Overbidding in Private Value Auctions" Experimental Economics, 20(4), 772-792.

[19] Gill, D. and V. Prowse (2012), "A Structural Analysis of Disappointment Aversion in a Real Effort Competition" American Economic Review, 102(1), 469-503.

[20] Gneezy, U., L. Goette, C. Sprenger and F. Zimmermann (2017), "The Limits of Expectations-Based Reference Dependence" Journal of the European Economic Association, 15(4), 861-876.

[21] Goette, L., A. Harms and C. Sprenger (2014), "Randomizing Endowments: An Experimental Study of Rational Expectations and Reference-Dependent Preferences" Working Paper.

[22] Greiner, B. (2015) "Subject Pool Recruitment Procedures: Organizing Experiments with ORSEE" Journal of the Economic Science Association, 1(1), 114-125.

[23] GuL, F. (1991) “A Theory of Disappointment Aversion" Econometrica, 59(3), 667-686.

[24] Harstad, R. (2000), "Dominant Strategy Adoption and Bidders' Experience with Pricing Rules" Experimental Economics, 3(3), 261-280.

[25] Heffetz, O. and J. List (2014), "Is the Endowment Effect an Expectations Effect?" Journal of the European Economic Association, 12(5), 1396-2014.

[26] Horowitz, J. (2006) "The Becker-DeGroot-Marschak mechanism is not necessarily incentive compatible, even for non-random goods" Economic Letters, 93(1), 6-11. 
[27] Kagel, J., R. Harstad and D. Levin (1987), "Information Impact and Allocation Rules in Auctions with Affiliated Private Values: A Laboratory Study" Econometrica, 55(6), 1275-1304.

[28] Kagel, J. and D. Levin (1993), "Independent Private Value Auctions: Bidder Behaviour in First-, Second- and Third-Price Auctions with Varying Numbers of Bidders" Economic Journal, 103(419), 868-879.

[29] Kahneman, D. and A. Tversky (1979), "Prospect Theory: An Analysis of Decision under Risk" Econometrica, 47(2), 263-291.

[30] Kahneman, D., J.L. Knetsch and R. Thaler (1990), "Experimental Tests of the Endowment Effect and the Coase Theorem" Journal of Political Economy, 98(6), 13251348.

[31] Kahneman, D., J.L. Knetsch and R. Thaler (1991), “Anomalies: The Endowment Effect, Loss Aversion, and Status Quo Bias" Journal of Economic Perspectives, 5(1), 193-206.

[32] Karle, H., G. Kirchsteiger and M. Peitz (2015), "Loss Aversion and Consumption Choice: Theory and Experimental Evidence" American Economic Journal: Microeconomics, $7(2), 101-120$.

[33] Köszegi, B. and M. Rabin (2006), "A Model of Reference-Dependent Preferences" Quarterly Journal of Economics, 121(4), 1133-1165.

[34] Köszegi, B. and M. Rabin (2007), "Reference-Dependent Risk Attitudes" American Economic Review, 97(4), 1047-1073.

[35] Lange, A. and A. RAtan (2010), "Multi-dimensional Reference-dependent Preferences in Sealed-bid auctions: How (most) Laboratory Experiments Differ from the Field" Games and Economic Behavior, 68(2), 634-645.

[36] Li, S. (2017) "Obviously Strategy-Proof Mechanisms" American Economic Review, $107(11), 3257-3287$.

[37] Loomes, G. and R. Sudgen (1986), "Disappointment and Dynamic Consistency in Choice under Uncertainty" Review of Economic Studies, 53(2), 271-282.

[38] Mazar, N., B. Köszegi and D. Ariely (2014), "True Context-dependent Preferences? The Causes of Market-dependent Valuations" Journal of Behavioral Decision Making, 27(3), 200-208. 
[39] Morgan, J., K. Steiglitz and G. Reis (2003) "The Spite Motive and Equilibrium Behavior in Auctions" Contributions to Economic Analysis 83 Policy, 2(1), Article 5.

[40] Ozbay, E. and E. Ozbay (2007), "Auctions with Anticipated Regret: Theory and Evidence" American Economic Review, 97(4), 1407-1418.

[41] Pope, D. and M. Schweitzer (2011), "Is Tiger Woods Loss Averse? Persistent Bias in the Face of Experience, Competition, and High Stakes" American Economic Review, 101(1), 129-157.

[42] Rabin, M. and G. Weizsäcker (2009), "Narrow Bracketing and Dominated Choices" American Economic Review, 99(4), 1508-1543.

[43] Sprenger, C. (2015), "An Endowment Effect for Risk: Experimental Tests of Stochastic Reference Points" Journal of Political Economy, 123(6), 1456-1499.

[44] Starmer, C. and R. Sudgen (1991), "Does the Random-Lottery Incentive System Elicit True Preferences? An Experimental Investigation " American Economic Review, 81(4), 971-978.

[45] Thaler, R. (1985), "Mental Accounting and Consumer Choice" Marketing Scence, $4(3), 199-214$.

[46] Thaler, R. (1999), "Mental Accounting Matters" Journal of Behavioral Decision Making, 12(3), 183-206.

[47] Tymula, A., E. Woelbert and P. Glimcher (2016) "Flexible Valuations for Consumer Goods as Measured by The Becker-DeGroot-Marschak Mechanism" Journal of Neuroscience, Psychology, and Economics, 9(2), 65-77.

[48] Tversky, A. and D. Kahneman (1981), "The Framing of Decisions and the Psychology of Choice" Science, 211(4481), 453-458.

[49] Tversky, A. and D. Kahneman (1991), "Loss Aversion in Riskless Choice: A Reference-Dependent Model" Quarterly Journal of Economics, 106(4), 1039-1061.

[50] Vickrey, W. (1961), "Counterspeculation and Competitive Sealed Tenders" Journal of Finance, 16(1), 8-37.

[51] Wenner, L. (2015), "Expected Prices as Reference Points - Theory and Experiments" European Economic Review, 75, 60-79. 


\section{A Appendix: Proofs}

Proof of Proposition 1: Part (i) follows from Lange and Ratan (2010). For part (ii), begin by noticing that the expected payment of type- $\theta$ bidder reads

$$
\begin{aligned}
\mathcal{T}(\theta) & =\int_{0}^{\theta} \beta^{*}(x, n) d H^{n-1}(x) \\
& +\Lambda \underbrace{\left\{\left[1-2 H^{n-1}(\theta)\right] \int_{0}^{\theta} \beta^{*}(x, n) d H^{n-1}(x)+2 \int_{0}^{\theta} H^{n-1}(x) \beta^{*}(x, n) d H^{n-1}(x)\right\}}_{:=C(\theta)} .
\end{aligned}
$$

Moreover, the envelope theorem implies that

$$
\mathcal{T}(\theta)=(1-\Lambda)\left\{H^{n-1}(\theta) \theta-\int_{0}^{\theta} H^{n-1}(x) d x\right\}+\Lambda\left\{\left(H^{n-1}(\theta)\right)^{2} \theta-\int_{0}^{\theta}\left(H^{n-1}(s)\right)^{2} d s\right\} .
$$

Similarly, for the risk-neutral case the envelope theorem implies that

$$
\int_{0}^{\theta} x d H^{n-1}(x)=H^{n-1}(\theta) \theta-\int_{0}^{\theta}\left(H^{n-1}(s)\right) d s .
$$

Combining (6), (7) and (8) we obtain

$$
\int_{0}^{\theta} \beta^{*}(x, n) d H^{n-1}(x)=(1-\Lambda) \int_{0}^{\theta} x d H^{n-1}(x)+\Lambda\left\{\left(H^{n-1}(\theta)\right)^{2} \theta-\int_{0}^{\theta}\left(H^{n-1}(s)\right)^{2} d s\right\}-\Lambda C(\theta) .
$$

Therefore, we have that

$$
\begin{aligned}
\int_{0}^{\theta}\left[\beta^{*}(x, n)-x\right] d H^{n-1}(x) & =\Lambda\left\{\left(H^{n-1}(\theta)\right)^{2} \theta-\int_{0}^{\theta} x d H^{n-1}(x)-\int_{0}^{\theta}\left(H^{n-1}(s)\right)^{2} d s\right\}-\Lambda C(\theta) \\
& =\Lambda\left\{\int_{0}^{\theta} H^{n-1}(s)\left[1-H^{n-1}(s)\right] d s-H^{n-1}(\theta)\left[1-H^{n-1}(\theta)\right] \theta\right\}-\Lambda C(\theta)
\end{aligned}
$$

where the last step follow from (8). Observe further that $\frac{d\left(\int_{0}^{\theta} \beta^{*}(x, n) d H^{n-1}(x)-\int_{0}^{\theta} x d H^{n-1}(x)\right)}{d \theta}=$ $(n-1) H^{n-2}(\theta) h(\theta)\left(\beta^{*}(\theta, n)-\theta\right)$. Therefore, $\beta^{*}(\theta, n)>\theta$ if and only if

$$
\Lambda\left\{\int_{0}^{\theta} H^{n-1}(s)\left[1-H^{n-1}(s)\right] d s-H^{n-1}(\theta)\left[1-H^{n-1}(\theta)\right] \theta\right\}^{\prime}-\Lambda C^{\prime}(\theta)>0 .
$$

To prove part (ii) notice that the sign of the expression on the LHS of (9) depends on the sign of the following expression

$$
\Lambda(n-1) H^{n-2}(\theta) h(\theta)\left[2 H^{n-1}(\theta)-1\right] \theta-\Lambda C^{\prime}(\theta) .
$$


Fix now a $\theta$ such that $H^{n-1}(\theta) \leq 0.5$. A sufficient condition for expression (10) to be negative is that $C^{\prime}(\theta) \geq 0$. We have

$$
\begin{aligned}
C^{\prime}(\theta) & =(n-1) H^{n-2}(\theta) h(\theta)\left[\beta^{*}(\theta, n)-2 \int_{0}^{\theta} \beta^{*}(x, n) d H^{n-1}(x)\right] \geq 0 \\
& \Leftrightarrow \beta^{*}(\theta, n) \geq 2 \int_{0}^{\theta} \beta^{*}(x, n) d H^{n-1}(x) \\
& \Leftrightarrow \beta^{*}(\theta, n)-2\left[H^{n-1}(\theta) \beta^{*}(\theta, n)-\int_{0}^{\theta} \frac{\partial \beta^{*}(x, n)}{\partial x} H^{n-1}(x) d x\right] \geq 0 \\
& \Leftrightarrow \beta^{*}(\theta, n)\left[1-2 H^{n-1}(\theta)\right]+2 \int_{0}^{\theta} \frac{\partial \beta^{*}(x, n)}{\partial x} H^{n-1}(x) d x \geq 0 .
\end{aligned}
$$

As $\beta^{*}(\theta, n)$ is increasing in $\theta$, it follows that $C^{\prime}(\theta) \geq 0$ for any $\theta \leq \theta^{m}$. Hence, for any such type expression (10) is negative, which proves the second claim.

To prove the third claim observe that

$\begin{aligned}\left.\beta(\theta, n)\right|_{\theta=\bar{\theta}} & =\theta+\frac{2 \Lambda}{(1+\Lambda)^{2}} \int_{0}^{\bar{\theta}} x\left\{1-\Lambda\left[1-2 H(x)^{n-1}\right]\right\}(n-1) H(x)^{n-2} e^{\left(\frac{2 \Lambda\left(1-H(x)^{n-1}\right)}{1+\Lambda}\right)} h(x) d x \\ & >\theta\end{aligned}$

where the inequality follows from Assumption 1. Hence, since $\beta(\theta, n)$ is continuous in $\theta$, there exists a positive measure of types $\left[\theta^{\prime \prime}, \bar{\theta}\right]$ for which $\beta^{*}(\theta, n)>\theta$.

Differentiating $\beta^{*}(\theta, n)$ with respect to $n$ yields

$$
\begin{aligned}
& \frac{\partial \beta^{*}(\theta, n)}{\partial n}=\frac{2 \Lambda H(\theta)^{n-1} \theta \ln H(\theta)}{1+\Lambda} \\
+ & \frac{2 \Lambda}{(1+\Lambda)^{2}} \int_{0}^{\theta} x \gamma(\theta, x)\left\{(n-1) \frac{2 \Lambda}{1+\Lambda}\left[H(\theta)^{n-1} \ln H(\theta)-H(x)^{n-1} \ln H(x)\right]+[1+(n-1) \ln H(x)]\right\} h(x) d x
\end{aligned}
$$

where $\gamma(\theta, x)=e^{\left(\frac{2 \Lambda\left(H(\theta)^{n-1}-H(x)^{n-1}\right)}{1+\Lambda}\right)} H(x)^{n-2}\left[1-\Lambda+2 \Lambda H(x)^{n-1}\right]$. It's easy to see that $\frac{2 \Lambda H(\theta)^{n-1} \theta \ln H(\theta)}{1+\Lambda}<0$. Therefore, a sufficient condition for the whole derivative to be negative is that the integral is negative.

First, notice that

$$
1+(n-1) \ln H(x)<0 \Leftrightarrow H(x)<e^{-\frac{1}{n-1}}
$$


Next, notice that $H(x)^{n-1} \ln H(x)$ is decreasing if

$$
\begin{aligned}
\frac{d}{d x}\left(H(x)^{n-1} \ln H(x)\right) & =(n-1) H^{n-2}(x) h(x) \ln H(x)+\frac{H(x)^{n-1} h(x)}{H(x)}<0 \\
& \Leftrightarrow(n-1) H^{n-2}(x) h(x)[(n-1) \ln H(x)+1]<0 \\
& \Leftrightarrow H(x)<e^{-\frac{1}{n-1}} .
\end{aligned}
$$

This proves the fourth claim.

Finally, in order to prove $(\mathrm{v})$ let $\bar{\beta}(n):=\int_{0}^{\bar{\theta}} \beta^{*}(x, n) h(x) d x$ and notice that

$$
\frac{d \bar{\beta}(n)}{d n}=\int_{0}^{\bar{\theta}} \frac{\partial \beta^{*}(x, n)}{\partial n} h(x) d x
$$

From claim (iv), we know that $\frac{\partial \beta^{*}(x, n)}{\partial n}<0$ for all $x$ such that $H(x)<e^{-\frac{1}{n-1}}$. Moreover, notice that $e^{-\frac{1}{n-1}}$ is increasing in $n$ and $\lim _{n \rightarrow \infty}\left(e^{-\frac{1}{n-1}}\right)=1$. Hence, $\frac{d \bar{\beta}(n)}{d n}<0$ if $h^{\prime}(\theta) \leq 0$ or if $n$ is large. 


\section{B Appendix: Replication of Sprenger (2015)}

This task followed the same procedures as in Sprenger (2015) who designed an experiment aimed at distinguishing the KR model from models of Disappointment Aversion (Bell, 1985; Loomes and Sudgen, 1986; Gul, 1991). The exact procedures are explained in Sprenger (2015) and here we just outline the intuition. The task was designed in price list style with 21 decision rows. Each decision row was a choice between a certain amount and a gamble. In each session, subjects were randomly separated into two groups. Half the subjects were asked a series of certainty equivalents for a fixed gamble while the other half were asked a series of probability equivalents for a fixed certain amount. Crucially, the fixed option (the gamble in one case and the certain amount in the other) was always displayed on the left. Sprenger (2015) argues that the option presented on the left becomes a reference point against which the other option is compared. The unique prediction of the KR model is that people will be risk-averse when the reference point is a certain amount and risk-neutral when the reference point is a gamble. ${ }^{18}$ Thus comparing choices in these two treatments allows us to perform a test of the KR model of expectations-based reference-dependent preferences at the population level. Our participants completed Conditions 1.1 and 2.1 in Sprenger (2015). See Figure 4 or Table 1 in Sprenger (2015). All participants were paid according to one randomly selected choice from the task.

In figure 5 we classify each participant into one of three risk-attitude types: risk seeking $(\mathrm{S})$, risk neutral $(\mathrm{N})$ and risk averse $(\mathrm{A})$ using individuals' switching points as the classification criterion. Then, separately for each set of questions, we counted how many subjects fell in each category. Figure 5(a) shows the results. We find that the number of subjects that are classified as risk averse is significantly larger when the fixed option was the certain amount than when the fixed option was the gamble. As this classification of responses is rather strict, following Sprenger (2015) we then re-classified each participant's risk-attitude type by using a wider interval for risk neutrality. Under this classification, individuals are classified as risk-neutral if their switching point interval includes risk neutrality or if it is one row above or below. The results are shown in Figure 5(b). Just as in Sprenger (2015), we find that also under this less strict classification the number of subjects classified as risk averse when the fixed option was the certain amount is significantly larger than when the

\footnotetext{
${ }^{18}$ As explained in Sprenger (2015), this prediction holds under what Köszegi and Rabin $(2006,2007)$ call unacclimating personal equilibrium (UPE). Yet, following most of the literature, our analysis of the auction game uses choice-acclimating personal equilibrium (CPE) as solution concept. Hence, our experimental tasks impose (and test the implications of) two different solution concepts. However, we think that each solution concept is the correct one for the task at hand. In the auction, subjects' bids directly affect the distribution of outcomes. Hence, it is conceivable that a subject's reference point is determined (at least partially) by his own bid. In the decision task, instead, subjects are presented with a series of binary choices that they have to make, with one of the two options appearing in every choice, and always being displayed first. In this case, as also argued by Sprenger (2015), it is conceivable that the reference point is (at least partially) determined by the fixed, first option.
} 
Panel A : Probability Equivalent

\begin{tabular}{|c|c|c|c|c|c|c|}
\hline & \multirow{2}{*}{$\begin{array}{c}\text { Option A } \\
\text { Certain Payment of } \$ 10\end{array}$} & & \multirow[t]{2}{*}{ or } & \multicolumn{3}{|c|}{ Option B } \\
\hline & & & & Chance of $\$ 0$ & Chance of $\$ 30$ & \\
\hline 1) & $\$ 10$ & $\square$ & or & 100 in 100 & 0 in 100 & $\square$ \\
\hline 2) & $\$ 10$ & $\square$ & or & 95 in 100 & 5 in 100 & $\square$ \\
\hline 3) & $\$ 10$ & $\square$ & or & 90 in 100 & 10 in 100 & $\square$ \\
\hline 4) & $\$ 10$ & $\square$ & or & 85 in 100 & 15 in 100 & $\square$ \\
\hline 5) & $\$ 10$ & $\square$ & or & 80 in 100 & 20 in 100 & $\square$ \\
\hline 6) & $\$ 10$ & $\square$ & or & 75 in 100 & 25 in 100 & $\square$ \\
\hline 7) & $\$ 10$ & $\square$ & or & 70 in 100 & 30 in 100 & $\square$ \\
\hline 8) & $\$ 10$ & $\square$ & or & 65 in 100 & 35 in 100 & $\square$ \\
\hline 9) & $\$ 10$ & $\square$ & or & 60 in 100 & 40 in 100 & $\square$ \\
\hline 10) & $\$ 10$ & $\square$ & or & 55 in 100 & 45 in 100 & $\square$ \\
\hline 11) & $\$ 10$ & $\square$ & or & 50 in 100 & 50 in 100 & $\square$ \\
\hline 12) & $\$ 10$ & $\square$ & or & 45 in 100 & 55 in 100 & $\square$ \\
\hline 13) & $\$ 10$ & $\square$ & or & 40 in 100 & 60 in 100 & $\square$ \\
\hline 14) & $\$ 10$ & $\square$ & or & 35 in 100 & 65 in 100 & $\square$ \\
\hline 15) & $\$ 10$ & $\square$ & $o r$ & 30 in 100 & 70 in 100 & $\square$ \\
\hline 16) & $\$ 10$ & $\square$ & or & 25 in 100 & 75 in 100 & $\square$ \\
\hline 17) & $\$ 10$ & $\square$ & or & 20 in 100 & 80 in 100 & $\square$ \\
\hline 18) & $\$ 10$ & $\square$ & or & 15 in 100 & 85 in 100 & $\square$ \\
\hline 19) & $\$ 10$ & $\square$ & or & 10 in 100 & 90 in 100 & $\square$ \\
\hline 20) & $\$ 10$ & $\square$ & $o r$ & 5 in 100 & 95 in 100 & $\square$ \\
\hline 21) & $\$ 10$ & $\square$ & or & 0 in 100 & 100 in 100 & $\square$ \\
\hline
\end{tabular}

Panel B : Certainty Equivalent

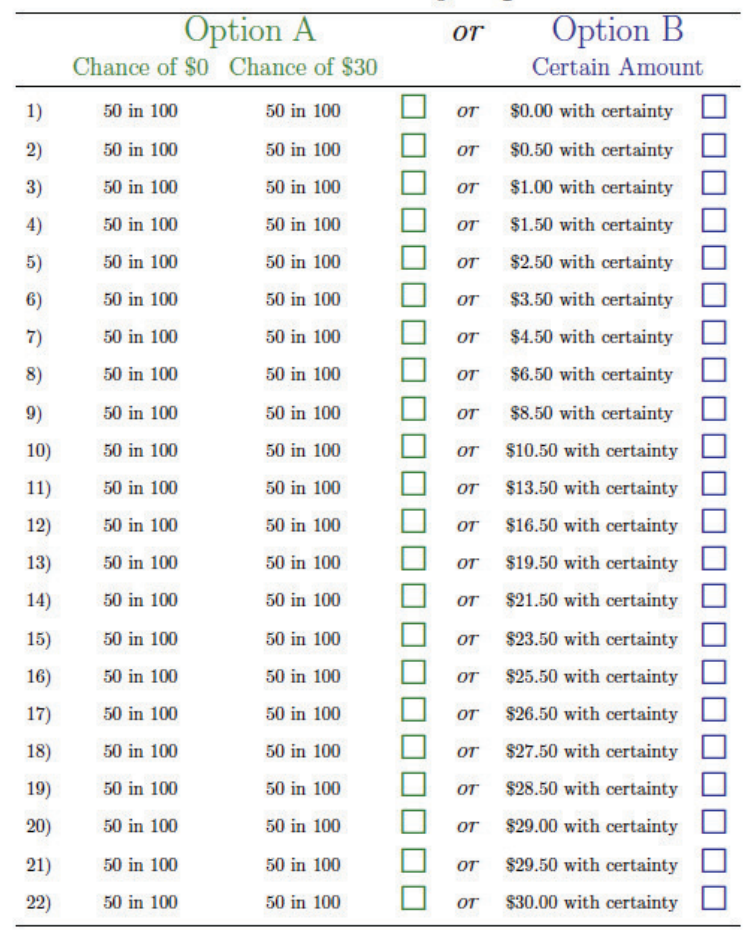

Figure 4: A list of choices in the lottery task. Half of the participants were shown Panel A and the other half Panel B questions. Reprinted from Sprenger (2015).

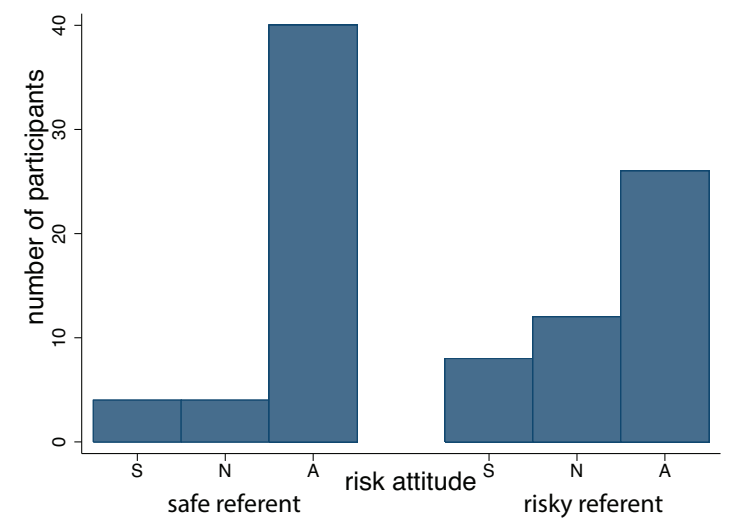

(a) Risk Attitude Classification

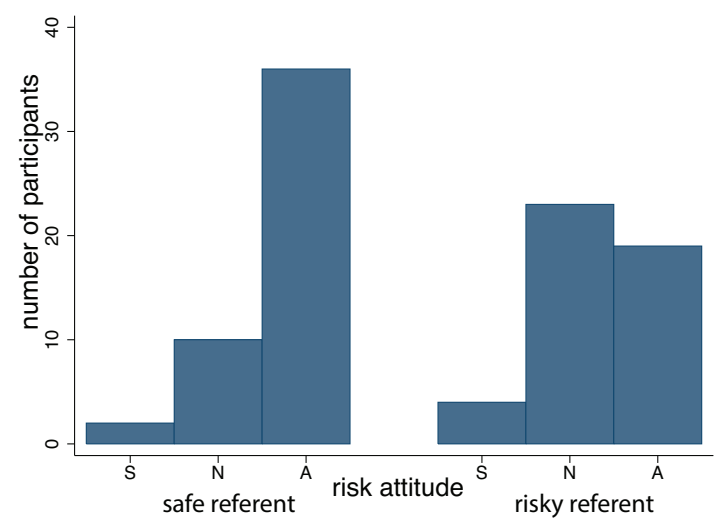

(b) Risk Attitude Classification - Wide Interval

Figure 5: Classification of participants into risk seeking " $\mathrm{S}$ ", risk neutral "N" and risk averse "A" based on their lottery choices. Two participants with multiple switching points are excluded. There are 48 participants who completed the task with a safe referent and 46 participants with a risky referent. Subfigure (a) is based on the classifications using the interval of a participant's switch point. Subfigure (b) is based on a wider interval classification including the switch point $+/$ - one choice.

fixed option was the gamble. Moreover, when the fixed option is the gamble the majority of subjects are now classified as risk neutral. Therefore, we conclude that also in this task subjects in our study behaved consistently with the predictions of the KR model. 


\section{Appendix: Additional Tables}

Table 7: Summary statistics of self-reported familiarity, ownership, desire to purchase, financial constraints and valuation for each good. Familiarity with the good and desire to purchase are measured on a 6-point Likert scale where 1 (6) indicates the lowest (highest) familiarity and desire to purchase. Ownership is a binary variable taking value of $1(0)$ when individual reported to (not) own the good. Constrained is a binary variable equal to 1 (0) when subject reported to be budget constrained (unconstrained) when bidding in the auction. Valuation is self-reported willingness to pay for the good. The exact wording of the questionnaire is available in Appendix F.

\begin{tabular}{lccccc}
\hline & familiarity & ownership & desire & constrained & valuation \\
\hline \multirow{5}{*}{$\begin{array}{l}\text { movie } \\
\text { boombox }\end{array}$} & 5.55 & 0.38 & 3.32 & 0.09 & 15.07 \\
hoodie & 3.63 & 0.05 & 3.60 & 0.27 & 22.06 \\
& 5.40 & 0.28 & 3.70 & 0.16 & 20.20 \\
movie & \multicolumn{2}{c}{ others' } & prize unknown treatment & & \\
t-shirt & 5.49 & 0.15 & 4.16 & 0.15 & 19.25 \\
mug & 4.90 & 0.32 & 3.27 & 0.05 & 16.24 \\
& 4.90 & 0.21 & 2.56 & 0.05 & 10.14 \\
money voucher & & & & & \\
\hline
\end{tabular}


Table 8: Participants' intended use for each prize. Totals in "others' prize unknown" treatment are lower because some participants did not provide an answer.

\begin{tabular}{|c|c|c|c|c|c|}
\hline & own use & gift & resell & other & total \\
\hline \multicolumn{6}{|c|}{ others' prize same treatment } \\
\hline movie & 55 & 27 & 6 & 8 & 96 \\
\hline boombox & 45 & 27 & 13 & 11 & 96 \\
\hline hoodie & 70 & 11 & 5 & 10 & 96 \\
\hline \multicolumn{6}{|c|}{ others' prize unknown treatment } \\
\hline movie & 67 & 17 & 4 & 3 & 91 \\
\hline t-shirt & 65 & 22 & 4 & 4 & 95 \\
\hline mug & 63 & 26 & 2 & 4 & 95 \\
\hline voucher & 167 & 9 & 2 & 13 & 191 \\
\hline total & 532 & 139 & 36 & 53 & 760 \\
\hline
\end{tabular}

Table 9: Effect of auction size on bids. 3 participants (6 participants) is an indicator variable equal to one when the participant is bidding in an auction with 3 (6) bidders. The reference category is auction with 12 bidders. Subject-good fixed effects are included. Standard errors are reported in parentheses. ${ }^{*} p<.10,{ }^{* *} p<.05,{ }^{* * *} p<.01$.

\begin{tabular}{lrrr|rrr|r}
\hline & \multicolumn{3}{c|}{ others' prize same } & \multicolumn{3}{c|}{ others' prize unknown } & \\
& movie & boombox & hoodie & movie & t-shirt & \multicolumn{1}{c}{ mug } & voucher \\
\hline 3 participants & $0.99^{*}$ & 1.06 & $1.02^{*}$ & 0.81 & $1.03^{*}$ & $1.67^{* * *}$ & 0.01 \\
& $(0.50)$ & $(0.71)$ & $(0.57)$ & $(0.63)$ & $(0.57)$ & $(0.45)$ & $(0.33)$ \\
6 participants & 0.81 & 0.68 & $1.19^{* *}$ & -0.16 & $1.07^{*}$ & $1.17^{* *}$ & 0.35 \\
& $(0.50)$ & $(0.71)$ & $(0.57)$ & $(0.63)$ & $(0.57)$ & $(0.45)$ & $(0.33)$ \\
constant & $15.11^{* * *}$ & $18.64^{* * *}$ & $17.02^{* * *}$ & $18.14^{* * *}$ & $13.82^{* * *}$ & $9.76^{* * *}$ & $15.31^{* * *}$ \\
& $(0.36)$ & $(0.51)$ & $(0.40)$ & $(0.45)$ & $(0.40)$ & $(0.32)$ & $(0.24)$ \\
\hline No. of obs & 288 & 288 & 288 & 288 & 288 & 288 & 576 \\
\hline
\end{tabular}


Table 10: Tobit analysis of the effect of auction size on bids. 3 participants (6 participants) is an indicator variable equal to one when the participant is bidding in an auction with 3 (6) bidders. The reference category is auction with 12 bidders. Censored at bid=30. Random effects included. Standard errors in parentheses. ${ }^{*} p<.10,{ }^{* *} p<.05,{ }^{* * *} p<.01$

\begin{tabular}{lrrr|rrr|r}
\hline & \multicolumn{3}{c|}{ others' prize same } & \multicolumn{2}{c|}{ others' prize unknown } & \\
& movie & boombox & hoodie & movie & t-shirt & \multicolumn{1}{c}{ mug } & voucher \\
\hline 3 participants & $1.17^{* *}$ & 1.29 & $1.18^{*}$ & 1.00 & $1.08^{*}$ & $1.77^{* * *}$ & -0.03 \\
& $(0.56)$ & $(0.94)$ & $(0.71)$ & $(0.79)$ & $(0.66)$ & $(0.49)$ & $(0.38)$ \\
6 participants & 0.86 & 0.88 & $1.45^{* *}$ & -0.28 & $1.20^{*}$ & $1.27^{* *}$ & 0.42 \\
& $(0.56)$ & $(0.94)$ & $(0.71)$ & $(0.78)$ & $(0.66)$ & $(0.49)$ & $(0.38)$ \\
constant & $15.67^{* * *}$ & $20.97^{* * *}$ & $19.07^{* * *}$ & $19.62^{* * *}$ & $14.76^{* * *}$ & $10.08^{* * *}$ & $16.06^{* * *}$ \\
& $(1.11)$ & $(1.48)$ & $(1.49)$ & $(1.27)$ & $(1.25)$ & $(1.09)$ & $(0.83)$ \\
\hline No. of obs & 288 & 288 & 288 & 288 & 288 & 288 & 576 \\
\hline
\end{tabular}

Table 11: Effect of auction size on bids excluding subjects who always overbid on the voucher. 3 participants (6 participants) is an indicator variable equal to one when the participant is bidding in an auction with 3 (6) bidders. The reference category is auction with 12 bidders. Subject-good random effects are included. Standard errors are reported in parentheses. ${ }^{*} p<.10,{ }^{* *} p<.05,{ }^{* * *} p<.01$.

\begin{tabular}{lrrr|rrr|r}
\hline & \multicolumn{3}{c|}{ others' prize same } & \multicolumn{2}{c|}{ others' prize unknown } & \\
& movie & boombox & hoodie & movie & t-shirt & \multicolumn{1}{c}{ mug } & voucher \\
\hline 3 participants & $1.21^{* * *}$ & 0.55 & $1.33^{* *}$ & $1.42^{* *}$ & $1.68^{* *}$ & $1.67^{* * *}$ & 0.29 \\
& $(0.44)$ & $(0.70)$ & $(0.63)$ & $(0.70)$ & $(0.68)$ & $(0.43)$ & $(0.40)$ \\
6 participants & $0.89^{* *}$ & 0.64 & $1.42^{* *}$ & 1.04 & $1.14^{*}$ & $0.98^{* *}$ & 0.41 \\
& $(0.44)$ & $(0.70)$ & $(0.63)$ & $(0.70)$ & $(0.68)$ & $(0.43)$ & $(0.40)$ \\
constant & $14.34^{* * *}$ & $18.43^{* * *}$ & $16.83^{* * *}$ & $16.28^{* * *}$ & $10.86^{* * *}$ & $7.44^{* * *}$ & $12.90^{* * *}$ \\
& $(1.05)$ & $(1.18)$ & $(1.20)$ & $(1.21)$ & $(1.20)$ & $(1.06)$ & $(0.76)$ \\
\hline No. of obs & 246 & 246 & 246 & 198 & 198 & 198 & 444 \\
\hline
\end{tabular}


Table 12: Effect of auction size on bids excluding subjects who felt constrained when bidding. 3 participants (6 participants) is an indicator variable equal to one when the participant is bidding in an auction with 3 (6) bidders. The reference category is auction with 12 bidders. Subject-good random effects are included. Standard errors are reported in parentheses. ${ }^{*} p<.10,{ }^{* *} p<.05,{ }^{* * *} p<.01$

\begin{tabular}{lrrr|rrr|r}
\hline & \multicolumn{3}{c|}{ experiment 1 } & \multicolumn{3}{c|}{ experiment2 } & \\
& movie & boombox & hoodie & movie & t-shirt & mug & voucher \\
\hline 3 participants & 0.80 & 0.69 & 0.72 & -0.01 & 0.59 & $1.73^{* * *}$ & 0.25 \\
& $(0.54)$ & $(0.84)$ & $(0.60)$ & $(0.60)$ & $(0.46)$ & $(0.47)$ & $(0.33)$ \\
6 participants & 0.74 & 1.24 & $1.15^{*}$ & -0.95 & 0.45 & $1.36^{* * *}$ & 0.22 \\
& $(0.54)$ & $(0.84)$ & $(0.60)$ & $(0.60)$ & $(0.46)$ & $(0.47)$ & $(0.33)$ \\
constant & $14.77^{* * *}$ & $15.99^{* * *}$ & $15.91^{* * *}$ & $17.60^{* * *}$ & $13.81^{* * *}$ & $9.84^{* * *}$ & $14.51^{* * *}$ \\
& $(1.01)$ & $(1.23)$ & $(1.18)$ & $(1.07)$ & $(1.07)$ & $(1.03)$ & $(0.80)$ \\
\hline No. of obs & 261 & 210 & 243 & 246 & 273 & 273 & 459 \\
\hline
\end{tabular}

Table 13: Effect of auction size on bids. The analysis excludes participants who indicated that they would resell the prize if they win. 3 participants (6 participants) is an indicator variable equal to one when the participant is bidding in an auction with 3 (6) bidders. The reference category is auction with 12 bidders. Subject-good random effects are included. Standard errors are reported in parentheses. ${ }^{*} p<.10,{ }^{* *} p<.05,{ }^{* * *} p<.01$

\begin{tabular}{lrrr|rrr|r}
\hline & \multicolumn{3}{c|}{ others' prize same } & \multicolumn{2}{c|}{ others' prize unknown } & \\
& movie & boombox & hoodie & movie & t-shirt & \multicolumn{1}{c}{ mug } & voucher \\
\hline 3 participants & $1.08^{* *}$ & 1.08 & 0.93 & 0.86 & 0.92 & $1.59^{* * *}$ & 0.02 \\
& $(0.53)$ & $(0.79)$ & $(0.59)$ & $(0.65)$ & $(0.58)$ & $(0.46)$ & $(0.34)$ \\
6 participants & 0.87 & 0.78 & $1.14^{*}$ & 0.02 & $0.97^{*}$ & $1.10^{* *}$ & 0.37 \\
& $(0.53)$ & $(0.79)$ & $(0.59)$ & $(0.65)$ & $(0.58)$ & $(0.46)$ & $(0.34)$ \\
constant & $15.63^{* * *}$ & $20.09^{* * *}$ & $17.37^{* * *}$ & $17.98^{* * *}$ & $13.79^{* * *}$ & $9.90^{* * *}$ & $15.21^{* * *}$ \\
& $(1.01)$ & $(1.10)$ & $(1.10)$ & $(1.03)$ & $(1.08)$ & $(1.02)$ & $(0.73)$ \\
\hline No. of obs & 270 & 249 & 273 & 276 & 276 & 282 & 570 \\
\hline
\end{tabular}


Table 14: Number of participants that increase $(\uparrow)$, decrease $(\downarrow)$ or keep their bid constant (-) as number of participants changes. Changes of bids equal to or less than $\$ 3$ are treated as no change.

\begin{tabular}{|c|c|c|c|c|c|c|c|c|c|}
\hline & $\begin{array}{c}3 \text { to } 12 \\
\downarrow\end{array}$ & $\uparrow$ & - & $\begin{array}{c}3 \text { to } \\
\downarrow\end{array}$ & $\uparrow$ & - & $\begin{array}{c}6 \text { to } 12 \\
\downarrow\end{array}$ & $\uparrow$ & - \\
\hline \multicolumn{10}{|c|}{ others' prize same } \\
\hline movie & 20 & 8 & 68 & 10 & 10 & 76 & 17 & 6 & 73 \\
\hline boombox & 18 & 15 & 63 & 14 & 13 & 69 & 16 & 12 & 68 \\
\hline hoodie & 18 & 15 & 63 & 10 & 11 & 75 & 18 & 11 & 67 \\
\hline \multicolumn{10}{|c|}{ others' prize unknown } \\
\hline movie & 16 & 11 & 69 & 15 & 11 & 70 & 12 & 19 & 65 \\
\hline t-shirt & 14 & 10 & 72 & 11 & 10 & 75 & 15 & 8 & 73 \\
\hline mug & 22 & 8 & 66 & 12 & 5 & 79 & 16 & 7 & 73 \\
\hline voucher & 14 & 22 & 156 & 12 & 19 & 161 & 20 & 16 & 156 \\
\hline all real goods & 108 & 67 & 401 & 72 & 60 & 444 & 94 & 63 & 419 \\
\hline
\end{tabular}

Table 15: Effect of auction size on bids excluding bidders with top $10 \%$ of the bids in each auction. Ties (also at \$30) result in different number of observations per good. 3 participants (6 participants) is an indicator variable equal to one when the participant is bidding in an auction with 3 (6) bidders. The reference category is auction with 12 bidders. Subject-good random effects are included. Standard errors are reported in parentheses. ${ }^{*} p<.10,{ }^{* *} p<.05,{ }^{* * *} p<.01$.

\begin{tabular}{lrrr|rrr|r}
\hline & \multicolumn{3}{c}{ others' prize same } & \multicolumn{2}{c|}{ others' prize unknown } & \\
& movie & boombox & \multicolumn{1}{c}{ hoodie } & movie & \multicolumn{1}{c}{ t-shirt } & \multicolumn{1}{c}{ mug } & voucher \\
\hline \multirow{3}{*}{ Coef./se } & Coef./se & Coef./se & Coef./se & Coef./se & Coef./se & Coef./se \\
\hline \multirow{3}{*}{ p participants } & $1.12^{* *}$ & 1.30 & $1.27^{*}$ & 0.93 & $1.15^{*}$ & $1.76^{* * *}$ & -0.00 \\
& $(0.57)$ & $(0.88)$ & $(0.71)$ & $(0.73)$ & $(0.64)$ & $(0.48)$ & $(0.37)$ \\
constant & $0.95^{*}$ & 0.84 & $1.49^{* *}$ & -0.19 & $1.20^{*}$ & $1.24^{* * *}$ & 0.39 \\
& $(0.57)$ & $(0.88)$ & $(0.71)$ & $(0.73)$ & $(0.64)$ & $(0.48)$ & $(0.37)$ \\
& $13.22^{* * *}$ & $16.02^{* * *}$ & $13.82^{* * *}$ & $16.28^{* * *}$ & $11.74^{* * *}$ & $8.65^{* * *}$ & $13.53^{* * *}$ \\
No. of obs & $(0.95)$ & $(1.15)$ & $(1.12)$ & $(1.03)$ & $(1.00)$ & $(0.94)$ & $(0.70)$ \\
\hline
\end{tabular}

